\title{
Auction Theory: A Guide to the Literature
}

Forthcoming, Journal of Economic Surveys, 1999

\author{
Paul Klemperer \\ Nuffield College, Oxford University, UK \\ Int Tel: +44 1865278588 \\ Int Fax: +44 1865278557
}

email: paul.klemperer@economics.ox.ac.uk

March 1999

\begin{abstract}
This paper, forthcoming in Journal of Economic Surveys, provides an elementary, non-technical, survey of auction theory, by introducing and describing some of the critical papers in the subject. (The most important of these are reproduced in a companion book, The Economic Theory of Auctions, Paul Klemperer (ed.), Edward Elgar (pub.), 1999.) We begin with the most fundamental concepts, and then introduce the basic analysis of optimal auctions, the revenue equivalence theorem, and marginal revenues. Subsequent sections address risk-aversion, affiliation, asymmetries, entry, collusion, multi-unit auctions, double auctions, royalties, incentive contracts, and other topics. Appendices contain technical details, some simple numerical examples, and bibliographies.
\end{abstract}

\section{Keywords}

Auctions, Bidding, Auction Theory, Common-value Auctions, Private-value Auctions, Mechanism Design.

JEL No. D44 (Auctions)

Acknowledgments: I would like to thank my friends and colleagues, including Mark Armstrong, Chris Avery, Alan Beggs, Sushil Bikhchandani, Simon Board, Jeremy Bulow, Peter Cramton, Nils Henrik von der Fehr, Tim Harford, Jon Levin, Ulrike Malmendier, Flavio Menezes, Meg Meyer, Paul Milgrom, John Morgan, John Riley, Mark Satterthwaite, Daniel Sgroi, Margaret Stevens, John Thanassoulis, Chris Wallace, Lucy White, Bob Wilson, the editor (Stuart Sayer) and a referee for helpful advice. 


\section{Introduction}

Auction theory is important for practical, empirical, and theoretical reasons.

First, a huge volume of economic transactions is conducted through auctions. Governments use auctions to sell treasury bills, foreign exchange, mineral rights including oil fields, and other assets such as firms to be privatized. Government contracts are typically awarded by procurement auctions, and procurement auctions are also often used by firms buying inputs or subcontracting work; in these cases, of course, the auctioneer is seeking a low price rather than a high price. Houses, cars, agricultural produce and livestock, art and antiques are commonly sold by auction. Other economic transactions, for example takeover battles, are auctions in effect if not in name. There has recently been an explosion of interest in designing new auction forms, for example to sell radio spectrum licences ${ }^{1}$ and in using auctions to set up new markets, for example for electricity, transport etc. ${ }^{2}$

Second, because auctions are such simple and well-defined economic environments, they provide a very valuable testing-ground for economic theory - especially of game theory with incomplete information - that has been increasingly exploited in recent years. Major empirical research efforts have focused on auctions for oil drilling rights, timber, and treasury bills, ${ }^{3}$ and there has also been an upsurge of interest in experimental work on auctions. ${ }^{4}$

Finally, auction theory has been the basis of much fundamental theoretical work: it has been important in developing our understanding of other methods of price formation, most prominently posted prices (as, for example, observed in most retail stores) and negotiations in which both the buyer and seller are actively involved in determining the price. There are close connections between auctions and competitive markets. ${ }^{5} \quad$ There is also a very close analogy between the theory of optimal auctions and the theory of monopoly pricing, ${ }^{6}$ and auction-theory can also help develop models of oligopolistic pricing. ${ }^{7} \quad$ Auction-theoretic models and techniques also apply to

\footnotetext{
${ }^{1}$ See McAfee and McMillan (1994,1996), Klemperer (1998) and Milgrom (forthcoming).

${ }^{2}$ For example, Green and Newbery (1992) discuss the use in the U.K. electricity market of the auction mechanism first analysed in Klemperer and Meyer (1989).

${ }^{3}$ See Laffont (1997).

${ }^{4}$ See Kagel (1995).

${ }^{5}$ See Section 8(c).

${ }^{6}$ See Section 4.

${ }^{7}$ Appendix B of Bulow and Klemperer (1999b) provides one illustration.
} 
non-price means of allocation including queues, wars of attrition, lobbying contests, other kinds of tournaments, and rationing. ${ }^{8}$

\subsection{Plan of this Paper}

This paper provides an elementary survey of auction theory, by introducing and describing some of the critical papers in the subject. The most important of these are reproduced in a companion book, The Economic Theory of Auctions, ${ }^{9}$ for which this paper was originally prepared.

For readers completely new to auction theory, the remainder of this section provides a brief resume of the simplest concepts. The subsequent sections correspond to the sections into which The Economic Theory of Auctions is organized. Section 2 discusses the early literature, and Section 3 introduces the more recent literature. Section 4 introduces the analysis of optimal auctions and auction theory's most fundamental result: the revenue equivalence theorem. It also describes how the concept of "marginal revenue" can inform auction theory. (Technical details are in appendices.) This section focuses on auction theory's basic model of a fixed set of symmetric, risk-neutral bidders with independent information who bid independently for a single object. Most of the remainder of this paper is about the effects of relaxing one or more of these assumptions. Section 5 permits risk-aversion; Section 6 allows for correlation or affiliation of bidders' information (with technical details in an appendix); Section 7 analyses cases with asymmetric bidders; Section 8 considers bidders who have costs of entering an auction, and addresses other issues pertaining to the number of bidders; Section 9 asks what is known if there are possibilities for collusion among bidders; and Section 10 considers multiunit auctions. Section 11 looks at auctions for incentive contracts, and auctions in which contestants may bid on royalty rates or quality levels in addition to prices. Section 12 reviews the literature on double auctions, and Section 13 briefly considers other topics including budget constraints, externalities between bidders, jump bidding, the war of attrition, and competing auctioneers. Section 14 is about testing the theory, and Section 15 concludes. Appendices A, B, and C provide

\footnotetext{
${ }^{8}$ Queues and lobbying contests are examples of all-pay auction models; see, for example, Holt and Sherman (1982) and Riley (1989). The war of attrition can also be modelled as a kind of all-pay auction; see Section 13(d), below, and Bulow and Klemperer (1999a). Insights from auction theory can explain rationing; see Section 8(b), below, and Gilbert and Klemperer (1999).

${ }^{9}$ Klemperer (1999).
} 
technical details about the revenue equivalence theorem, marginal revenues, and affiliation, respectively. Appendix D provides some numerical examples illustrating these Appendices. Appendix E provides a bibliography organised according to the sections of this paper.

\subsection{The Standard Auction Types}

Four basic types of auctions are widely used and analyzed: the ascending-bid auction (also called the open, oral, or English auction), the descending-bid auction (used in the sale of flowers in the Netherlands and so also called the Dutch auction by economists), the first-price sealed-bid auction, and the second-price sealed-bid auction (also called the Vickrey auction by economists). ${ }^{10,11}$ In describing their rules we will focus for simplicity on the sale of a single object.

In the ascending auction, the price is successively raised until only one bidder remains, and that bidder wins the object at the final price. This auction can be run by having the seller announce prices, or by having the bidders call out prices themselves, or by having bids submitted electronically with the best current bid posted. In the model most commonly used by auction theorists (often called the Japanese auction), the price rises continuously while bidders gradually quit the auction. Bidders observe when their competitors quit, and once someone quits, she is not let back in. There is no possibility for one bidder to pre-empt the process by making a large "jump bid". We will assume this model of the ascending auction except where stated otherwise. ${ }^{12}$

The descending auction works in exactly the opposite way: the auctioneer starts at a very high price, and then lowers the price continuously. The first bidder who calls out that she will accept the current price wins the object at that price. ${ }^{13}$

\footnotetext{
${ }^{10}$ Confusingly, the second-price sealed-bid auction is sometimes called a Dutch auction by investment bankers.

${ }^{11}$ Cassady's (1967) book provides a detailed, although now somewhat dated, account of many of the contemporaneous auction institutions.

${ }^{12}$ Antiques and artwork are commonly sold using versions of the ascending auction, and houses are sometimes sold this way, too.

${ }^{13}$ For example, in Dutch flower auctions, the potential buyers all sit in a room at desks with buzzers connected to an electronic clock at the front of the room. The interior of the clock has information about what is being sold and the price at which the auction starts. Once the auction begins, a series of lights around the edge of the clock indicate to what percentage of the original asking price the good has fallen. As soon as one bidder buzzes in, she gets the flowers at the price indicated on the clock. (Except that, if there are several lots of the same flowers from the same seller available that morning, the buyer can choose to buy only some of the available lots, and the rest will be re-auctioned.) Fish are sold in a similar way in Israel, as is tobacco in Canada.
} 
In the first-price sealed-bid auction each bidder independently submits a single bid, without seeing others' bids, and the object is sold to the bidder who makes the highest bid. The winner pays her bid (that is, the price is the highest or "first" price bid). ${ }^{14}$

In the second-price sealed-bid auction, also, each bidder independently submits a single bid, without seeing others' bids, and the object is sold to the bidder who makes the highest bid. However, the price she pays is the second-highest bidder's bid, or "second price". This auction is sometimes called a Vickrey auction after William Vickrey, who wrote the seminal (1961) paper on auctions. ${ }^{15}$

For reasons we will explain shortly, the ascending and descending auctions are sometimes referred to as open second-price and open first-price auctions, respectively.

\subsection{The Basic Models of Auctions}

A key feature of auctions is the presence of asymmetric information. ${ }^{16}$ (With perfect information most auction models are relatively easy to solve.)

In the basic private-value model each bidder knows how much she values the object(s) for sale, but her value is private information to herself.

In the pure common-value model, by contrast, the actual value is the same for everyone, but bidders have different private information about what that value actually is. For example, the value of an oil-lease depends on how much oil is under the ground, and bidders may have access to different geological "signals" about that amount. In this case a bidder would change her estimate of the value if she learnt another bidder's

\footnotetext{
${ }^{14}$ First-price sealed-bid auctions are used in auctioning mineral rights in government-owned land; they are also sometimes used in the sales of artwork and real estate. This method is also often used in procurement (that is, competing contractors submit prices and the lowest bidder wins and receives her price for fulfilling the contract). U.K. Treasury securities are sold through the multi-unit equivalent of the first-price auction (every winner pays her own bid), and U.S. Treasury auctions used to be run this way too, though recently the U.S. Treasury has also been experimenting with a multi-unit version of the second-price sealed-bid auction.

${ }^{15}$ This auction form is used for most auctions of stamps by mail, and is also used for other goods in some auctions on the internet (see Lucking-Reiley, 1998), but it is much less commonly used than the other standard forms (see Rothkopf, Teisberg and Kahn, 1990 for some discussion why); it is commonly studied in part because of its attractive theoretical properties. A multi-unit version is sometimes used by governments when selling foreign exchange and by companies when buying back shares. Economists usually model the multi-unit version by assuming the price paid is the highest losing bid, since this has theoretical properties analogous to those of the single-unit second-price case. In practice the price paid is often that of the lowest winning bidder.

${ }^{16}$ The appropriate concept of equilibrium is therefore Bayesian-Nash equilibrium. That is, each player's strategy is a function of her own information, and maximizes her expected payoff given other players' strategies and given her beliefs about other players' information. See, for example, Gibbons (1992).
} 
signal, in contrast to the private-value case in which her value would be unaffected by learning any other bidder's preferences or information.

A general model encompassing both these as special cases assumes each bidder receives a private information signal, but allows each bidder's value to be a general function of all the signals. ${ }^{17}$ For example, your value for a painting may depend mostly on your own private information (how much you like it) but also somewhat on others' private information (how much they like it) because this affects the resale value and/or the prestige of owning it.

\subsection{Bidding in the Standard Auctions}

Consider first the descending auction. Note that although we described this as a dynamic game, each bidder's problem is essentially static. Each bidder must choose a price at which she will call out, conditional on no other bidder having yet called out; and the bidder who chooses the highest price wins the object at the price she calls out. Thus this game is strategically equivalent to the first-price sealed-bid auction, ${ }^{18}$ and players' bidding functions are therefore exactly the same. ${ }^{19}$ This is why the descending auction is sometimes referred to as an open first-price auction.

Now with private values, in the ascending auction, it is clearly a dominant strategy to stay in the bidding until the price reaches your value. The next-to-last person will drop out when her value is reached, so the person with the highest value will win at a price equal to the value of the second-highest bidder. Furthermore, a little reflection shows that in a second-price sealed-bid private-values auction it is optimal for a player to bid her true value, whatever other players do. ${ }^{20}$ In other words "truth telling" is

\footnotetext{
${ }^{17}$ That is, bidder $i$ receives signal $t_{i}$ and would have value $v_{i}\left(t_{1}, \ldots, t_{n}\right)$ if all bidders' signals were available to her. In the private-value model $v_{i}\left(t_{1}, \ldots, t_{n}\right)$ is a function only of $t_{i}$. In the pure commonvalue model $v_{i}\left(t_{1}, \ldots, t_{n}\right)=v_{j}\left(t_{1}, \ldots, t_{n}\right)$, for all $t_{1}, \ldots, t_{n}$. (If $i$ 's actual value $V_{i}\left(t_{1}, \ldots, t_{n}, s_{1}, \ldots, s_{k}\right)$ is also a function of other information $s_{1}, \ldots, s_{k}$, then of course $v_{i}\left(t_{1}, \ldots, t_{n}\right)=E\left\{V_{i}\left(t_{1}, \ldots, t_{n}, s_{1}, \ldots, s_{k}\right) \mid\right.$ $\left.t_{1}, \ldots, t_{n}\right\}$ is just $i$ 's estimated value, but for most purposes it does not matter whether $v_{i}\left(t_{1}, \ldots, t_{n}\right)$ is an estimated or an actual value.)

${ }^{18}$ That is, the set of strategies available to a player is the same in the descending auction as in the first-price sealed-bid auction. Choosing any given bid yields the same payoffs in both games as a function of the other players' bids.

${ }^{19}$ To solve for the bidding strategies, the direct method is to examine a player's first-order condition in which she trades off her probability of winning (which increases with her bid) with her profit conditional on winning (which decreases with her bid). Note 120 in Appendix A illustrates the method. For the independent-signal case a faster and more elegant approach is to use the revenue equivalence theorem, see Appendix A. Appendix D gives examples.

${ }^{20}$ To confirm this, consider bidding $v-x$ when your true value is $v$. If the highest bid other than yours is $w$, then if $v-x>w$ you win the auction and pay $w$, just as if you bid $v$. If $w>v$ you lose
} 
a dominant strategy equilibrium (and so also a Nash equilibrium), so here, too, the person with the highest value will win at a price equal to the value of the secondhighest bidder. This is why the ascending auction is sometimes referred to as an open second-price auction. However, this equivalence applies only for private values, or if there are just two bidders. With any common components to valuations and more than two bidders, players learn about their values from when other players quit an ascending auction and condition their behaviour on this information.

A key feature of bidding in auctions with common-values components is the winner's curse: each bidder must recognize that she wins the object only when she has the highest signal (in symmetric equilibrium). Failure to take into account the bad news about others' signals that comes with any victory can lead to the winner paying more, on average, than the prize is worth, and this is said to happen often in practice. In equilibrium, bidders must adjust their bids downwards accordingly.

Appendix D provides examples of equilibrium bidding strategies (and the winner's curse) in the standard auctions, in both private- and common-value contexts.

\subsection{Terminology}

Since the equivalence of descending and first-price sealed-bid auctions is completely general in single-unit auctions, and ascending and second-price sealed-bid auctions are also equivalent under many conditions (and have similar properties more broadly) we will often refer to the two kinds of auctions simply as first-price and second-price respectively.

Also, we will refer to any model in which a bidder's value depends to some extent on other bidders' signals as a common-value model. However, note that some authors reserve the term "common-value" to refer only to the special case when all bidders' actual values are identical functions of the signals (what we called the pure commonvalue case). Also (and somewhat inconsistently) we will use the term almost common

the auction and get nothing, just as if you bid $v$. But if $v>w>v-x$, bidding $v-x$ causes you to lose the auction and get nothing, whereas if you had bid $v$, you would have won the auction and paid $w$ for a net surplus of $v-w$. So you never gain, and might lose, if you bid $v-x$.

Now consider bidding $v+x$ when your true value is $v$. If the highest bid other than yours is $w$, then if $v>w$ you win and pay $w$, just as if you bid $v$. If $w>v+x$ you lose and pay nothing, just as if you bid $v$. But if $v+x>w>v$, having bid $v+x$ causes you to "win" an auction you otherwise would have lost, and you have to pay $w>v$ so you get negative surplus. So bidding $v+x$ may hurt you compared with bidding $v$, but it never helps you. 
values to mean almost pure common values.

Finally, there is no formal distinction between normal auctions, in which the auctioneer is the seller and the bidders are buyers who have values for the object(s) sold, and procurement auctions, where the auctioneer is a buyer and the bidders are sellers who have costs of supplying the object(s) bought. To avoid confusion we will generally adopt the former perspective (that the auctioneer is the seller) even when discussing papers that are couched in terms of the latter perspective.

\section{Early Literature}

Auctions have been used from time immemorial, ${ }^{21}$ but they entered the economics literature relatively recently. Remarkably, the first treatment that recognized the game-theoretic aspects of the problem ${ }^{22}$ also made enormous progress in analyzing it including developing some special cases of the celebrated Revenue Equivalence Theorem (see below): Vickrey's 1961 and 1962 papers were deservedly a major factor in his 1996 Nobel prize ${ }^{23}$ and the 1961 paper, especially, is still essential reading.

Other influential early work was performed by Shubik and his coauthors, and by Wilson and his student, Ortega-Reichert.

Griesmer, Levitan and Shubik (1967) analyse the equilibrium of a first-price auction in which contestants' valuations are drawn from uniform distributions with different supports, while Wilson (1969) introduced the (pure) common-value model and developed the first closed-form equilibrium analysis of the winner's curse. ${ }^{24}$

Ortega-Reichert's (1968) PhD thesis contains the seeds of much future work, but

\footnotetext{
${ }^{21}$ Shubik (1983) provides an attractively written historical sketch going back to the Babylonian and Roman empires. Most famously, the whole Roman empire was sold by ascending auction in A.D. 193 by the Praetorian Guards; the winner, and therefore next Emperor, was Didius Julianus who reigned for just over two months before being overthrown and executed by Septimius Severus (an early and sad case of the winner's curse); see also notes 56, 106, and 107, and see Gibbon (1776), Vol I, Chap $\mathrm{V}$ for an account.

${ }^{22}$ There are slightly earlier studies in the operations research literature, especially Friedman (1956), but these treat the problem decision-theoretically with bidders estimating opponents' bidding strategies based on a naive model of past behavior.

${ }^{23} \mathrm{He}$ shared the prize with Jim Mirrlees whose 1971 paper, although couched in the context of the theory of optimal income taxation, developed techniques that were to prove critical to the later analysis of auctions. Vickrey's 1976 essay is an additional contribution to auction theory.

${ }^{24}$ Rothkopf (1969) addresses a similar problem to Wilson's, but implicitly restricts bidders' strategies to multiples of their estimated values (see Rothkopf (1980)). Capen et al (1971) is a well-known, more popular account of the winner's curse in practice that was immensely important in influencing bidding practice. Wilson (1967) is a precursor to Wilson (1969), but with a less natural equilibrium concept.
} 
the time was perhaps not ripe for it, and it unfortunately never reached publication. It is a pleasure to be able to publish a small part of it in The Economic Theory of Auctions: the chapter we publish considers a sequence of two first-price auctions in which the correlation of players' values for the two objects means that a player's bid for the first object conveys information about her value for the second object, and hence about her likely second bid. ${ }^{25}$ This analysis of a signalling game was enormously influential in, for example, guiding Milgrom and Roberts' (1982) analysis of limit pricing. ${ }^{26}$

However, with the exception of Vickrey's first (1961) article, these are no longer papers for the beginner.

\section{Introduction to the Recent Literature}

The full flowering of auction theory came only at the end of the 1970s with critical contributions from Milgrom, in papers both on his own and with Weber; from Riley, in papers with Maskin and with Samuelson; and from Myerson, among others, in addition to more from Wilson. These and contemporaneous contributions rapidly moved the field close to its current frontier. A very readable introduction to the state of the field by the late 1980s is in McAfee and McMillan (1987a). Another helpful introductory article is Maskin and Riley (1985) which manages to convey many of the key ideas in a few pages by focusing on the case with just two possible types of each of just two bidders. ${ }^{27,28}$

\section{The Basic Analysis of Optimal Auctions, Revenue Equivalence, and Marginal Revenues}

Roughly simultaneously, Myerson (1981) and Riley and Samuelson (1981) showed that Vickrey's results about the equivalence in expected revenue of different auctions

\footnotetext{
${ }^{25}$ See also the brief exposition of this work in Section 3.1 of Weber (1983) (see Section 10.3 of this survey and reprinted in that Part of The Economic Theory of Auctions).

${ }^{26}$ Personal communication from Paul Milgrom.

${ }^{27} \mathrm{~A}$ caveat is that the effects of correlated types cannot properly be discussed with just two types and this section of the paper is a little flawed and confusing. However Riley (1989) has a nice discussion of correlation with just three possible types of each bidder. See also Appendix C to this introduction.

${ }^{28}$ Other valuable survey material includes Milgrom $(1985,1987,1989)$, Weber (1985), Riley (1989), Maskin (1992), Wilson (1992), Harstad and Rothkopf (1994), Rothkopf (1994), and Wolfsetter (1996).
} 
apply very generally: $:^{29}$

Assume each of a given number of risk-neutral potential buyers of an object has a privately-known signal independently drawn from a common, strictly-increasing, atomless distribution. Then any auction mechanism in which (i) the object always goes to the buyer with the highest signal, and (ii) any bidder with the lowest-feasible signal expects zero surplus, yields the same expected revenue (and results in each bidder making the same expected payment as a function of her signal). ${ }^{30}$

Note that the result applies both to private-value models (in which a bidder's value depends only on her own signal), and to more general common-value models provided bidders' signals are independent.

Thus all the "standard" auctions, the ascending, the descending, the first-price sealed-bid, and the second-price sealed-bid, yield the same expected revenue under the stated conditions, as do many non-standard auctions such as an "all-pay" auction (in which every competitor pays her bid but only the highest bidder wins the object, as in a lobbying competition ${ }^{31}$ ).

This Revenue Equivalence Theorem result is so fundamental, so much of auction theory can be understood in terms of it, and at root the proof is so simple, that we offer an elementary proof of it in Appendix A. Any reader who is unfamiliar with the result, or who is under any misapprehension that it is a difficult one, is strongly urged to begin here. ${ }^{32}$

Riley and Samuelson's proof is less direct than that of Appendix A, but is still a simpler read than Myerson's. However, Myerson offers the most general treatment. Riley and Samuelson give more illustrations, but Myerson also develops the mathematics used to prove revenue equivalence a little further to show how to derive optimal

\footnotetext{
${ }^{29}$ Ortega-Reichert (1968) and Holt (1980) made some earlier extensions of Vickrey's work. Harris and Raviv (1981) covers much of the same ground as Myerson and Riley and Samuelson.

${ }^{30}$ This is not the most general statement. See Appendix A. To see the necessity of a strictly increasing or atomless distribution, carefully study Maskin and Riley (1985) or Harris and Raviv (1981). See Riley (1989) for revenue equivalence results for discrete distributions.

${ }^{31}$ Other examples that can be modelled as all-pay auctions include queues (see Holt and Sherman (1982)), legal battles (see Baye et al (1997)), and markets with consumer switching costs in which firms compete for the prize of selling to new unattached consumers by lowering their prices to their old locked-in customers (see especially Appendix B of Bulow and Klemperer (1999b) which explicitly uses the revenue equivalence theorem, and also Rosenthal (1980) and more generally, Klemperer (1995)). The war of attrition is also a kind of all-pay auction (see Section 13(d), below, and Bulow and Klemperer (1999a)).

${ }^{32}$ The Appendix also gives an example of solving for bidding strategies in more complex auctions by using revenue equivalence with an ascending auction.
} 
auctions (that is, auctions that maximise the seller's expected revenue) for a wide class of problems (see below).

Although this work was a remarkable achievement, there seemed to be little relationship to traditional price theory, which made the subject a difficult one for many economists. Bulow and Roberts (1989) greatly simplified the analysis of optimal auctions by showing that the problem is, in their own words, "essentially equivalent to the analysis of standard monopoly third-degree price discrimination. The auctions problem can therefore be understood by applying the usual logic of marginal revenue versus marginal cost."

In particular, it is helpful to focus on bidders' "marginal revenues". When bidders have independent private values, a bidder's "marginal revenue" is defined as the marginal revenue, at the bidder's value, of a firm whose demand curve is constructed from an arbitrarily large number of bidders whose values are independently drawn from the bidder's value distribution. Bulow and Roberts follow Myerson to show that under the assumptions of the revenue equivalence theorem the expected revenue from an auction equals the expected marginal revenue of the winning bidder(s).

Bulow and Klemperer $(1996)^{33}$ provide a simpler derivation of this result that also generalises its application. ${ }^{34}$ We give an elementary exposition of this material in Appendix B.

So in an optimal auction the objects are allocated to the bidders with the highest marginal revenues, just as a price-discriminating monopolist sells to the buyers with the highest marginal revenues (by equalizing the lowest marginal revenues sold to across different markets). And just as a monopolist should not sell below the price where marginal revenue equals marginal cost, so an auctioneer should not sell below a reserve price set equal to the value of the bidder whose marginal revenue equals the value to the auctioneer of retaining the unit. (The marginal revenue should be set equal to zero if the auctioneer, or monopolist, is simply maximizing expected revenues.)

\footnotetext{
${ }^{33}$ Also discussed in Section 8.2, and reprinted in that Part of The Economic Theory of Auctions.

${ }^{34}$ Bulow and Klemperer show how the result extends with common values, non-independent private information, and risk-aversion, while Bulow and Roberts restrict attention to the risk-neutral, independent, private-value, framework. See Appendix B.

The main thrust of Bulow and Klemperer's analysis is to develop a result about the value to an auctioneer of an additional bidder relative to the importance of constructing an optimal auction. (Ses Section 8.2 below.)
} 
These principles indicate how to run an optimal auction in the general case. ${ }^{35}$ Furthermore, when bidders are symmetric (that is, when their signals are drawn from a common distribution), any "standard" auction sells to the bidder with the highest signal. Therefore, if bidders with higher signals have higher marginal revenues - in the private-value context this is just equivalent to the usual assumption that a monopolist's marginal revenue is downward sloping 36 - then the winning bidder has the highest marginal revenue. So under the assumptions of the revenue equivalence theorem, and if bidders with higher signals have higher marginal revenues, all the standard auctions are optimal if the seller imposes the optimal reserve price.

Much of auction theory can be most easily understood by thinking in terms of marginal revenues and the relationship to the conditions for revenue equivalence; this paper will emphasise this perspective.

\section{Risk Aversion}

It is easy to see how risk-aversion affects the revenue equivalence result: in a second-price (or an ascending) auction, risk-aversion has no effect on a bidder's optimal strategy which remains to bid (or bid up to) her actual value. ${ }^{37}$ But in a first-price auction, a slight increase in a player's bid slightly increases her probability of winning at the cost of slightly reducing the value of winning, so would be desirable for a riskaverse bidder if the current bidding level were optimal for a risk-neutral bidder. So risk-aversion makes bidders bid more aggressively in first-price auctions. Therefore, since the standard auctions were revenue equivalent with risk-neutral bidders, a riskneutral seller faced by risk-averse bidders prefers the first-price auction to second-price sealed-bid or ascending auctions.

What if the auctioneer is risk-averse but the buyers are risk-neutral? Observe that the winner pays a price set by the runner-up in a second-price or ascending auction and, by revenue equivalence, must bid the expectation of this price in a first-price

\footnotetext{
${ }^{35}$ See Myerson and Bulow and Roberts for details.

${ }^{36}$ This amounts to the assumption that the monopolist's demand curve (or bidder's distribution function) is not too convex.

The assumption that bidders with higher signals have higher marginal revenues is more stringent in common-value contexts. See note 53.

${ }^{37}$ In a sealed-bid second-price auction with common-value components, a bidder bids her expected utility conditional on being tied for highest bidder (see Appendices C and D).
} 
auction. That is, conditional on the winner's actual information, the price is fixed in the first-price auction, and random but with the same mean in the second-price auction. So also unconditional on the winner's information, the price is riskier (but with the same mean) in the second-price auction. So a risk-averse seller prefers the first-price auction to the second-price sealed-bid auction and, for a similar reason, prefers the second-price sealed-bid auction to an ascending open auction. ${ }^{38}$

In another of the crucially important papers of the early 1980s, Maskin and Riley (1984) develop and generalise these results and then go on to consider the design of optimal auctions when the seller is risk-neutral and the buyers are risk-averse. ${ }^{39}$

However, although first-price auctions lead to higher prices with risk-averse buyers, this does not mean risk-averse buyers prefer second-price or ascending auctions since, as noted above, prices in the first-price auction are less risky. Matthews (1987) takes up the buyer's viewpoint; in fact, buyers are just indifferent with constant absolute risk aversion and tend to prefer the first-price auction if they have increasing absolute risk aversion or "affiliated values" (see next Section). ${ }^{40}$ These results can be developed by generalising the revenue equivalence result to a "utility equivalence" result that applies for risk-averse bidders. ${ }^{41}$

\section{Correlation and Affiliation}

Another crucial assumption in the basic analysis of optimal auctions is that each bidder's private information is independent of competitors' private information. We now relax this assumption while reverting to the assumption of risk-neutrality.

Section 7 of Myerson's extraordinary (1981) paper provides a very simple and instructive example showing that if bidders' private information is correlated, then the seller can construct a mechanism that yields for herself the entire social surplus that would be feasible if bidders' information were fully public! The mechanism offers each bidder a schedule of bets among which she is required to choose if she is to participate. For any given private information, the best of these bets will yield her exactly zero surplus in expectation, and by choosing it she is revealing her type so

\footnotetext{
${ }^{38}$ See Waehrer et al (1998) for the fullest exposition of the case of a risk-averse auctioneer.

${ }^{39}$ Matthews (1983) has many similar results. Holt (1980) is an earlier treatment.

${ }^{40}$ Matthews' paper is also important for its analysis of the case where the number of buyers is unknown. See Section 8.4 below.

${ }^{41}$ See Robert, Laffont, and Loisel (1994).
} 
that her surplus can be fully and efficiently extracted.

Cremer and McLean (1985) show that Myerson's result is very general, ${ }^{42}$ although it does seem to rely very heavily on assumptions such as risk-neutrality of the bidders, common knowledge of the distributions from which bidders' signals are drawn, the inability of bidders to collude, and the ability of the seller to credibly and costlessly communicate and enforce the auction's results (often including extracting large payments from losing bidders).

Since the "optimal mechanisms" seem unrealistic in this environment, how do standard auctions compare? Milgrom and Weber's remarkable (1982a) paper addresses this question in the context of developing a general theory of auctions with affiliated information. (Very roughly, bidders' signals are affiliated if a high value of one bidder's signal makes high values of other bidders' signals more likely. ${ }^{43}$ ) Since this paper is both very important in the literature and quite challenging for many readers, we given an elementary exposition of the main results as Appendix C, by starting from the revenue equivalence argument developed in Appendix A.

The main results are that ascending auctions lead to higher expected prices than sealed-bid second-price auctions, which in turn lead to higher expected prices than first-price auctions. ${ }^{44}$ The intuition is that the winning bidder's surplus is due to her private information. The more the price paid depends on others' information (the price depends on all other bidders' information in an ascending auction with common-value elements, and on one other bidder's information in a second-price sealed-bid auction), the more closely the price is related to the winner's information, since information is affiliated. So the lower is the winner's information rent and hence her expected surplus, and so the higher is the expected price.

For the same reason, if the seller has access to any private source of information, her optimal policy is precommit to revealing it honestly. The general principle that the expected price is raised by linking the price the winner pays to information that is affiliated with the winner's, is known as the Linkage Principle. ${ }^{45}$

One of the more striking results of the basic analysis of optimal auctions is that

\footnotetext{
${ }^{42}$ And Cremer and McLean (1988), McAfee, McMillan and Reny (1989) and McAfee and Reny (1992) show the result in even greater generality.

${ }^{43}$ See Appendix $\mathrm{C}$ for a precise definition.

${ }^{44}$ Appendix D gives an example.

${ }^{45}$ See also the discussion of Milgrom and Weber (1982c) in Section 10.3.
} 
if bidders have independent private values, the seller's reserve price is both independent of the number of bidders, and also well above the seller's cost. The reason is that the optimal reserve price is where marginal revenue equals the seller's cost, and a bidder's marginal revenue is independent of other bidders' marginal revenues when values are independent. However, if valuations are affiliated, more bidders implies more certainty about any one bidder's valuation conditional on other bidders' information, hence flatter marginal revenue curves, so a far higher proportion of bidders have marginal revenues in excess of the seller's cost. ${ }^{46}$ So the reserve price must be set lower. Levin and Smith (1996a) show that the optimal reserve price converges to the seller's true value as the number of bidders grows.

\section{Asymmetries}

Along with risk-neutrality, and independent private information, a third crucial assumption of the revenue equivalence theorem is that buyers' private values or signals were drawn from a common distribution. We now discuss relaxing the symmetry assumption. ${ }^{47}$

\subsection{Private Value Differences}

Myerson (1981) and Bulow and Roberts (1989) showed that a revenue-maximizing auction allocates objects to the bidder(s) with the highest marginal-revenue(s) rather than to those with the highest value(s). Recall from the standard theory of demand that a buyer on a given demand curve has a higher marginal revenue than any buyer with the same valuation on a demand curve that is higher everywhere due to being shifted out by a fixed amount horizontally. So a revenue-maximising auctioneer typically discriminates in favour of selling to bidders whose values are drawn from lower

\footnotetext{
${ }^{46}$ More precisely, consider setting an optimal reserve price after seeing all but the highest valuation. Affiliation implies the highest value is likely to be close to the second-highest, so the demand curve formed by a continuum of bidders with valuations drawn from the highest bidder's value distribution conditional on all others' values is rather flat just above the second value. Thus the final part of the highest-bidder's marginal revenue curve, conditional on all that has been observed, is also rather flat around the second-highest valuation. So even if the reserve price could be set based on all this information, it would usually be set very low. Hence it will also be set very low if it must be set prior to the auction.

${ }^{47}$ For results about the existence and uniqueness of equilibria in first-price auctions see Lebrun (1996), Maskin and Riley (1996a,b), Athey (1997) and Lizzeri and Persico (1998) (who consider a broader class of games). Some similar results can be developed following Bulow, Huang, and Klemperer (1995). Wilson (1998) derives explicitly the equilibrium of an ascending auction for a model with both private- and common-value components which allows asymmetries.
} 
distributions, that is, "weaker" bidders. McAfee and McMillan (1989) develop this point in a procurement context. ${ }^{48}$

Since in a first-price auction a bidder whose value is drawn from a weaker distribution bids more aggressively (closer to her actual value) than a bidder from a stronger distribution, ${ }^{49}$ a first-price auction also discriminates in favour of selling to the weaker bidder, in contrast to a second-price (or ascending) auction which always sells to the bidder with the higher valuation (in a private-values model). So it is plausible that a first-price auction may be more profitable in expectation, even though less efficient, than a second-price auction, when all the assumptions for revenue-equivalence except symmetry are satisfied. ${ }^{50}$ This is in fact often, though not always, the case. The large variety of different possible kinds of asymmetries makes it difficult to develop general results, but Maskin and Riley (1999) make large strides. ${ }^{51}$ A very useful brief discussion in Maskin and Riley (1985) summarises the situation as "roughly speaking, the sealed-bid auction generates more revenue than the open [second-price] auction when bidders have distributions with the same shape (but different supports), whereas the open auction dominates when, across bidders, distributions have different shapes but approximately the same support."

Maskin and Riley (1999) also show quite generally that "strong" buyers prefer the second-price auction, whereas "weak" buyers prefer the first-price auction. This may be important where attracting buyers to enter the auction is an important consideration; see below.

\subsection{Almost-Common-Values}

If valuations have common-value components the effects of asymmetries can be even more dramatic. If one player has a small advantage, for example, a slightly higher private value in a setting that is close to pure-common-values, that player will bid a little more aggressively. This strengthens the opponent's "winner's curse" (since

\footnotetext{
${ }^{48}$ See also Rothkopf, Harstad, and Fu (1997).

${ }^{49}$ In a first-price auction the first-order condition of a bidder with value $v$ considering raising her bid, $b$, by a small amount $\Delta b$ that would raise her probability of winning, $p$, by a small amount $\Delta p$ sets $(v-b) \Delta p-p \Delta b=0$. Weaker bidders have smaller probabilities of winning, $p$, and hence smaller "profit margins", $v-b$, when they do win.

${ }^{50}$ Maskin (1992) shows an ascending auction is efficient for a single good, even when valuations have common-value components, under a broad class of assumptions.

${ }^{51}$ The earliest analyses of asymmetric cases are in Vickrey (1961) and Griesmer et al (1967). Marshall et al (1994) and Riley and Li (1997) solve additional cases by numerical methods.
} 
winning against a more aggressive competitor is worse news about the actual value of a common value object), so the opponent will bid a little less aggressively in an ascending auction, so the first player's winner's curse is ameliorated and she can bid a little more aggressively still, and so on. Klemperer (1998) discusses a range of contexts in which, in consequence, an apparently small edge for one player translates into a very large competitive advantage in an ascending auction. The earliest specific example in the literature is Bikhchandani's (1988) demonstration that a small reputation advantage can allow a bidder to almost always win a pure-common-value auction, and that this reputational advantage may be very easy to sustain in a repeated context. Bulow, Huang and Klemperer (1999) demonstrates that having a small toehold can be an enormous advantage in a otherwise pure-common-values takeover battle.

The original stimulus for all this work is Milgrom (1981) ${ }^{52}$ which analyses equilibria in ascending auctions and, shows that there is a vast multiplicity in the pure-common values case, ranging from the symmetric equilibrium to equilibria in which an arbitrarily chosen player always wins. Adding some "grit" into the model, whether it be a small private-value component, a small reputation component, or a small ownership component, etc., selects one of these equilibria, but which equilibrium is selected depends on exactly how the pure-common-values model is perturbed. Thus an apparently small change in the environment can greatly increase a player's chance of winning.

Since the winner of an "almost-common-value" ascending auction may therefore often have the lower signal, and so typically the lower marginal revenue, ascending auctions may be very unprofitable in this context.

By contrast, in a first-price auction a small change to the symmetric model generally results in a small change to the (unique) symmetric equilibrium, so the bidder with the higher signal hence, typically, higher marginal revenue continues to (almost always) win. So the first-price auction is almost optimal for a revenue-maximizing auctioneer, and is much more profitable than an ascending auction, provided bidders with higher signals have higher marginal revenues. ${ }^{53}$

\footnotetext{
${ }^{52}$ Also discussed in Sections 7.3 and 8.3, and reprinted in Part 8.3 of The Economic Theory of Auctions.

${ }^{53}$ However, Bulow and Klemperer (1999c) show that the assumption that bidders with higher signals have higher marginal revenues is not innocuous in the common-values context. (In the private-values context the assumption is equivalent to the assumption of downward-sloping marginal revenue for a monopolist whose demand corresponds to the distribution of a bidder's signals; in common-value
} 
The effects of almost-common-values in ascending auctions are most extreme where there are also entry or bidding costs (see Section 8) in which case the disadvantaged bidder(s) may not enter at all, leaving the autioneer to face a single bidder, see Klemperer (1998).

\subsection{Information Advantages}

Another important form of asymmetry is that one player may have superior information. Here, again, Milgrom $(1981)^{54}$ is critically important, showing that in a pure-common-value setting a bidder with no private information makes no profits in equilibrium in a second-price auction. Milgrom and Weber (1982b) shows the same result (and much more) in the first-price context. ${ }^{55}$

\section{Entry Costs and the Number of Bidders}

\subsection{Endogenous Entry of Bidders}

In practical auction design, persuading bidders to take the time and trouble to enter the contest is a major concern, so we now endogenise the number of bidders and ask how it depends on the selling mechanism chosen. ${ }^{56}$

The first key result is that in a private-value setting that satisfies the revenueequivalence assumptions except for the presence of entry costs, bidders make the socially-correct decision about whether or not to enter any standard auction if the reserve price is set equal to the seller's valuation. To see this, note that the expected social value of the bidder being present is the probability she wins the auction times the difference between her value and the runner-up's value. But this is exactly the bid-

settings, bidders' values and hence marginal revenues depend on others' signals, and oligopolists' marginal revenues are not necessarily decreasing in other firms' outputs. In the pure-common-values (and almost-common-values) cases the assumption is related to the assumption of strategic substitutes, see Bulow and Klemperer (1999c) and also Bulow, Geanakoplos and Klemperer (1985a,b).)

Bulow and Klemperer (1999c) show that if in fact this assumption does not hold, then a number of standard presumptions are violated in the symmetric equilibrium of a pure-common-values ascending auction; for example, more bidders can lower expected profits (see note 63) selling more units can raise average price, and rationing (as in Initial Public Offerings) can raise expected price. Furthermore, even if the assumption on marginal revenue holds, these results arise in the almost-common values case.

${ }^{54}$ Also discussed in Sections 7.2 and 8.3, and reprinted in Part 8.3 of The Economic Theory of Auctions.

${ }^{55}$ See also Engelbrecht-Wiggans, Milgrom and Weber (1983).

${ }^{56}$ The Praetorians, when auctioning the Empire (see note 21), seem to have stipulated that the winning bidder could not punish the losers. This provision may have encouraged entry to the auction, although it would presumably reduce revenue from any exogenously fixed number of bidders. 
der's expected profit after entering a second-price auction, and so also, using revenue equivalence, in a very wide class of auctions including all standard auctions.

Furthermore, in a free-entry equilibrium in which ex-ante identical bidders enter to the point at which each expects zero profits net of the entry cost (and each finds out her private value subsequent to the entry decision ${ }^{57}$ ), the seller obtains the entire social surplus in expectation. So it also follows that running any standard auction with a reserve price equal to the seller's cost is revenue maximising for the seller. ${ }^{58}$

These results can be found in, for example, Levin and Smith $(1994)^{59}$ in a model in which bidders simultaneously make symmetric mixed-strategy entry decisions so that their expected profits are exactly zero. The results apply whether or not bidders observe how many others have chosen to enter before bidding in the auction, since revenue equivalence applies across and between both cases. ${ }^{60}$ The results also apply if entry is sequential but the number of firms is treated as a continuous variable so that entrants' expected profits are exactly zero. In other cases the fact that the number of entrants must be an integer means that the marginal entrant's expected profits may exceed zero, but Engelbrecht-Wiggans (1993) shows that this makes very little difference: the seller optimally adjusts the reserve price and/or sets an entry subsidy or fee that sucks up all the entrants' surplus while altering the number of entrants by at most one. ${ }^{61,62}$

In pure-common-value auctions, in marked contrast, the socially optimal number of bidders is obviously just one. Furthermore, Matthews (1984) shows that expected seller revenue can also be decreasing in the number of bidders in non-pathological pure-

\footnotetext{
${ }^{57}$ See Menezes and Monteiro (1997) for the case in which bidders know their private values prior to the entry decision.

${ }^{58}$ But the seller can increase social surplus, and hence her own expected revenue, if she can run a series of auctions. For example, she might announce an auction with a reserve price and the proviso that if the reserve is not met there will be a subsequent auction. Then there will be additional entrants in the second round if the good is not sold in the first round, that is, in the states in which the first-round entrants turned out to have low valuations. This increases social efficiency and seller revenue. See Burguet and Sákovics (1996) and also McAfee and McMillan (1988).

${ }^{59}$ Earlier related literature includes Engelbrecht-Wiggans (1987) and McAfee and McMillan (1987c). Levin and Smith (1996b) considers the seller's preference between standard auction forms when buyers are risk-averse; the auctioneer typically, but not always, prefers first-price to second-price auctions when bidders have entry costs.

${ }^{60}$ See Section 8.4 below.

${ }^{61}$ The same result extends to affiliated private value auctions.

${ }^{62}$ Furthermore, Bulow and Klemperer (1996) show in the same setting that an additional bidder is worth more than the ability to set an optimal reserve price against a given number of bidders. See Section 8.2 below.
} 
common-value settings, and Bulow and Klemperer (1999c) provide intuition for why this is natural by using marginal-revenue analysis. ${ }^{63}$ So both socially and privately, entry fees and reservation prices are much more desirable in common-value contexts. See Levin and Smith (1994) and also Harstad (1990).

Where bidders are asymmetric ex-ante, an auctioneer may wish to run an ex-post inefficient auction to attract weaker bidders to enter the contest. Thus Gilbert and Klemperer (1999) show that committing to ration output (that is, selling at a fixed price at which demand exceeds supply) may be more profitable than raising price to clear the market (that is, running an ascending auction that is ex-post efficient) because it attracts more buyers into the market. ${ }^{64,65}$

Finally, bidders can influence the number of their rivals through their own strategic behavior. In particular, Fishman (1988) demonstrates that it can be profitable for a bidder to commit to a high bid (for example, by making a pre-emptive "jump" bid in a takeover battle) to deter potential rivals from incurring the cost required to enter the contest. ${ }^{66}$

\subsection{The Value of Additional Bidders}

Bulow and Klemperer (1996) show that when bidders are symmetric, an additional bidder is worth more to the seller in an ascending auction than the ability to set a reserve price, provided bidders with higher signals have higher marginal revenues. They then demonstrate that, very generally in a private-value auction, and also in a wide class of common-value settings ${ }^{67}$ a simple ascending auction with no reserve price and

\footnotetext{
${ }^{63}$ The problem is that while the assumption that bidders with higher signals have higher marginal revenues usually holds in private-value settings, it often does not hold in pure-common-value settings. See note 53.

For a simple example consider the case where the common value equals the maximum of three signals $v_{i}, i=1,2,3$, each drawn independently from a uniform distribution on [0,1] and each known by a different bidder. By selling to an uninformed bidder the seller makes $\frac{9}{12}\left(=E \max \left\{v_{1}, v_{2}, v_{3}\right\}\right)$. Selling to a single informed bidder the maximum revenue equals $\frac{8}{12}\left(=E \max \left\{v_{2}, v_{3}\right\}\right)$ achieved by setting a reservation price at this level (an informed bidder with signal 0 will just be willing to pay this price). Selling to two informed bidders yields at most $\frac{7}{12}$ in expectation (by a slightly harder calculation). Selling to all three bidders yields at most $\frac{6}{12}$ in expectation (the expected second-highest signal).

${ }^{64}$ Or because it lowers the cost of persuading a given number of buyers to invest in participating in the market. Possible examples include the rationing of microchips, and split-award defense contracts.

${ }^{65}$ Similarly, Persico (1997) shows that bidders have more incentive to collect information prior to a first-price auction than prior to a second-price auction.

${ }^{66}$ Similarly, Daniel and Hirshleifer (1995) obtain jump bidding in an ascending auction when each successive bid is costly. See Section 13.3.

${ }^{67}$ In common-value settings higher signals would not imply higher marginal revenues. See note 53
} 
$N+1$ symmetric bidders is more profitable than any auction that can realistically be run with $N$ of these bidders. ${ }^{68}$ So it is typically worthwhile for a seller to devote more resources to expanding the market than to collecting the information and performing the calculations required to figure out the best mechanism.

\subsection{Information Aggregation with Large Numbers of Bidders}

An important strand of the auction literature has been concerned with the properties of pure-common-value auctions as the number of bidders becomes large. The question is: does the sale price converge to the true value, thus fully aggregating all of the economy's information even though each bidder has only partial information? If it does, it is then attractive to think of an auction model as justifying some of our ideas about perfect competition.

Wilson (1977)'s important early contribution showed that the answer is "yes" for a first-price auction under his assumptions. ${ }^{69}$ Milgrom (1981) obtained similar results for a second-price auction (or for a $(k+1)^{t h}$ price auction for $k$ objects) in his remarkable paper that contains a range of other significant results and which we have already mentioned in Sections 7.2 and 7.3. ${ }^{70}$

Matthews (1984) allows each bidder to acquire information at a cost. In his model, as the number of bidders becomes large the amount of information each obtains falls, but in such a way that the (first-price) sale price does not in general converge to the true value.

\subsection{Unknown Number of Bidders}

Matthews (1987) ${ }^{71}$ and McAfee and McMillan (1987b) both consider auctions when bidders with private values are uncertain about how many rivals they are competing with, ${ }^{72}$ and analyse how bidders' and the seller's preferences between the number of

to Section 7.2 .

${ }^{68} \mathrm{~A}$ Cremer and McLean (1985)-style mechanism is probably not a realistic one in a practical setting. See our discussion in Section 6, above, and also Bulow and Klemperer (1996) and Lopomo (1998).

${ }^{69}$ Milgrom (1979) gives a precise characterisation of the signal structures that imply Wilson's result.

${ }^{70}$ Pesendorfer and Swinkels (1997) shows that the sale price converges to the true value in a $(k+1)$ st price auction for $k$ objects under weaker assumptions than Wilson's, provided that the number of objects as well as the number of bidders becomes large.

${ }^{71}$ Also discussed in Section 5, and reprinted in that Part of The Economic Theory of Auctions.

${ }^{72}$ In Piccione and Tan (1996) the number of bidders is known, but the number of bidders with private information is uncertain. This paper also considers common-value settings. 
bidders being known or unknown depend on the nature of bidders' risk aversion and on whether bidders' signals are affiliated, etc. ${ }^{73}$

Finally, it is not hard to see that under the usual assumptions (risk-neutrality, independent signals, symmetry, etc.), the standard argument for revenue equivalence applies independent of whether the actual number of competitors is revealed to bidders before they $\operatorname{bid}^{74}$

\section{Collusion}

A crucial concern about auctions in practice is the ability of bidders to collude, but the theoretical work on this issue is rather limited.

Robinson (1985) makes the simple but important point that a collusive agreement may be easier to sustain in a second-price auction than in a first-price auction. Assuming, for simplicity, no problems in coming to agreement among all the bidders, or in sharing the rewards between them, and abstracting from any concerns about detection, etc., the optimal agreement in a second-price auction is for the designated winner to bid infinitely high while all the other bidders bid zero, and no other bidder has any incentive to cheat on this agreement. But to do as well in a first-price auction the bidders must agree that the designated winner bid an arbitrarily small amount, while all the others bid zero, and all the others then have a substantial incentive to cheat on the agreement. ${ }^{75}$

An important question is whether the cartel can find a mechanism that efficiently (and incentive-compatibly) designates the winner and divides the spoils by making appropriate sidepayments, when bidders have private information about their own values. McAfee and McMillan (1992)'s main result is that this is possible and can be implemented by a simple pre-auction if all the bidders in the auction are members of the cartel and they all have private values drawn from the same distribution. This result is very closely related to the demonstration in Cramton, Gibbons and Klemperer $(1987)^{76}$ that a partnership (for example, the gains from a cartel) can be efficiently

\footnotetext{
${ }^{73}$ McAfee and McMillan also consider optimal auctions for the case of risk-neutral bidders.

${ }^{74}$ See Harstad, Levin, and Kagel (1990) for explicit bidding functions for the standard auction forms when the assumptions for revenue equivalence apply. The revenue equivalence result is also a special case of results in Matthews (1987) and McAfee and McMillan (1987b).

${ }^{75}$ Milgrom (1987) develops a similar intuition to argue that repeated second-price auctions are more susceptible to collusion than repeated first-price auctions.

${ }^{76}$ Discussed in Section 12.2, and reprinted in that Part of The Economic Theory of Auctions.
} 
divided up.

McAfee and McMillan also analyse cartels that contain only a subgroup of the industry participants, and "weak cartels" that cannot make sidepayments between members, and consider how a seller should respond to the existence of a cartel. ${ }^{77}$

Although there are many fewer formal analyses of collusion than seem merited by the issue's practical importance, Hendricks and Porter (1989) is very useful informal survey of the circumstances and mechanisms facilitating collusion. They focus especially on methods of detecting collusion.

\section{Multiunit Auctions}

Most auction theory, and almost all of the work discussed this far, restricts attention to the sale of a single indivisible unit. The literature on the sale of multiple units is much less well developed, except for the case where bidders demand only a single unit each. It is, however, the most active field of current research in auction theory, ${ }^{78}$ so this is probably the section of this survey that will become obsolete most quickly.

\subsection{Optimal Auctions}

Maskin and Riley (1989) extend Myerson's (1981) analysis of optimal auctions to the case in which buyers have downward-sloping demand-curves, independently drawn from a one-parameter distribution, for quantities of a homogeneous good. ${ }^{79}$ They provide one of a number of expositions of revenue equivalence for the multiunit case, when buyers each want no more than a single unit.

\footnotetext{
${ }^{77}$ Graham and Marshall (1987) address similar issues and show how any subset of bidders can achieve efficient collusion if an outside agent is available to achieve ex-post budget balancing. (See also Graham, Marshall, and Richard (1990).) Mailath and Zemsky (1991) show how to achieve efficient collusion in second-price auctions, even among a subset of bidders who are not ex-ante identical and without the need for an outside agent, but using a more complicated mechanism. Hendricks, Porter, and Tan (1999) derive a necessary and sufficient condition for an efficient, incentive-compatible cartel in a common-value setting.

${ }^{78}$ Much current work has been stimulated by the recent government auctions of radio spectrum licenses (for mobile telephony, etc.), and emphasises the problem of selling heterogenous goods with complementarities between them, with common-value components to bidders' valuations, and perhaps also externalities between bidders. For discussion of the spectrum sales see McAfee and McMillan (1994, 1996), Klemperer (1998) (discussed in Section 7.2, and reprinted in that Part of The Economics of Auctions) and especially, Milgrom (forthcoming). Another large body of important work has been stimulated by treasury auctions. See Bikhchandani and Huang (1993) for a survey of treasury security markets.

${ }^{79}$ As for Myerson (1981), the analysis can be interpreted through marginal revenues, though it is not presented this way.
} 
Palfrey (1983) analyses a seller's (and buyer's) preferences between bundling heterogeneous objects and selling them unbundled; he shows the seller's incentive to bundle diminishes as the number of bidders increases. Very little progress has been made since Palfrey's paper on the problem of determining the seller-optimal auction for selling heterogeneous objects, but this topic is the subject of active current research. ${ }^{80}$

\subsection{Simultaneous Auctions}

Wilson (1979), in another of his papers that was many years ahead of its time, first analysed share auctions - auctions in which each bidder offers a schedule specifying a price for each possible fraction of the item (for example, a certain volume of Treasury notes). He showed that in a uniform-price auction (when all the shares are sold at the (same) price that equates the supply and demand of shares) there are Nash equilibria that look very collusive, in that they support prices that may be much lower than if the item were sold as an indivisible unit. The intuition is that bidders can implicitly agree to divide up the item at a low price by each bidding extremely aggressively for smaller quantities than her equilibrium share so deterring the others from bidding for more.

This intuition suggests (at least) two ways of "undoing" the equilibrium. One way is to run a discriminatory auction in which bidders pay the price they bid for each share; bidding aggressively for small quantities is then very costly, so bidders submit flatter demand curves which induce greater price competition at the margin. See Back and Zender (1993), who argue that discriminatory auctions are therefore likely to be far more profitable for a seller. ${ }^{81}$ Nevertheless, Anton and Yao (1992) show that implicit coordination is still possible in this kind of auction if bidders' values are non-linear in the volume purchased. ${ }^{82}$

A second way of undoing the low-price uniform-price equilibrium is to include some

\footnotetext{
${ }^{80}$ See, for example, Armstrong (1998) and Avery and Hendershott (1997), and Rothkopf, Pekec, and Harstad (1998).

${ }^{81}$ The section of Wilson's paper on discriminatory auctions is a little misleading about the relationship with uniform-price auctions.

Maxwell (1983) is earlier work extending Wilson's paper.

${ }^{82}$ Anton and Yao also use a private-value framework in contrast to Back and Zender's and Wilson's common-value setting. See also Bernheim and Whinston (1986) and Anton and Yao (1989) for related models without incomplete information about costs or values.
} 
randomness in demands (for example, from non-competitive bidders) or in the seller's supply. Klemperer and Meyer (1989) take this tack and show that sufficient supply uncertainty can reduce the multiplicity of uniform-price equilibria to a single equilibrium that is highly competitive if bidders' values are linear in their volumes purchased. ${ }^{83}$ They pose their model in an oligopoly setting, or equivalently a procurement auction, and allow non-linear (but publicly-known) costs; the model closely corresponds to the actual operation of electricity-supply auction markets. ${ }^{84}$

Klemperer and Meyer's model allows downward-sloping demand (in the procurement context) hence the quantity is endogenous to the bids (even absent demand uncertainty). Hansen (1988) considers endogenous quantity in the winner-take-all context, and shows that not only does the auctioneer prefer a first-price to a second-price auction (in a context where revenue equivalence would hold if the quantity were fixed) but the first-price auction is also socially more efficient and may even be preferred by the bidders. The intuition is that in first- and second-price auctions the quantity traded depends on the prices bid by the winner and the runner-up, respectively. So the first-price auction is more efficient (the quantity traded reflects the winner's cost or value) and provides greater incentive for aggressive bidding (a more aggressive bid not only increases the probability of winning, but also increases the quantity traded contingent on winning).

\subsection{Sequential Auctions}

The analysis of auctions where units are sold sequentially is well developed for the important special case in which no buyer is interested in more than one unit. In this case, if the units are homogeneous, and under the other usual assumptions, revenue equivalence holds whether the units are sold sequentially or simultaneously (Weber (1983), Maskin and Riley (1989), and Bulow and Klemperer (1994)).

Thus quite complex multi-unit auctions can be solved by using revenue equivalence to work out, at any point of the game, what players' strategies must be to yield them the same expected payoff as if all the remaining units were auctioned simultaneously

\footnotetext{
${ }^{83}$ Back and Zender (1993) argue that realistic amounts of uncertainty may nevertheless leave a continuum of equilibria. See Nyborg (1997) for further discussion and other arguments against the low-price equilibrium. Other related recent work on simultaneous multi-unit auctions includes Daripa (1996a,b), Engelbrecht-Wiggans and Kahn (1997, 1998) and Wang and Zender (1998).

${ }^{84}$ See, for example, the developments of Klemperer and Meyer's model in Bolle (1992), Green and Newbery (1992), and Green (1996).
} 
in a simple ascending auction.

Bulow and Klemperer (1994) use the revenue equivalence theorem in this way to solve for the dynamic price-path of a model of a stock market or housing market; the model would be intractably hard to solve by the direct method of writing down the first-order conditions for equilibrium in a dynamic program. The point of the paper is that rational, strategic, traders should be very sensitive to new information and so participate in rushes of trading activity (frenzies) that sometimes lead to crashes in the market price. However, it is the method rather than the specific application that deserves emphasis here.

A much simpler example is the sale of $k$ units through $k$ repetitions of a firstprice auction, with only the winning bid announced at each stage, to bidders with independent private values. Here, revenue equivalence tells us that at each stage each bidder just bids the expected $(k+1)$ st highest value, conditional on being a winner and on the information revealed so far, since this is what she would pay if all the remaining units were auctioned simultaneously in a standard ascending auction. It is easy to see that this is a martingale, that is, the price neither rises or falls over time, on average.

A large contribution of Milgrom and Weber's (1982c) seminal paper is to consider a wider class of sequential auctions (including first-price auctions, both with and without price-announcements, second-price auctions, and English auctions) under more general assumptions. They show that with affiliation and/or common-value elements the price path drifts upwards. The intuition for the effect of affiliation is essentially that of the Linkage Principle (see Section 6) ${ }^{85}$ This paper has not previously been published, but although it is unpolished (and the reader must beware of possible errors) it is a highly influential paper that it is gratifying to be able to publish at last in The Economic Theory of Auctions.

Milgrom and Weber's paper left a puzzle: contrary to the discussion above, it is more common to observe a downward drift in prices at auctions (see especially Ashenfelter (1989)). This discrepancy has spawned a small literature attempting to

\footnotetext{
${ }^{85}$ Note, however, that Perry and Reny (1998) show that the Linkage Principle need not hold if individuals can win more than one unit. The reason is that if (as in Milgrom and Weber's model) bidders desire at most one unit the underbidder is always a loser with pessimistic information, but in a multi-unit auction the underbidder for the marginal unit may already have won inframarginal units and have optimistic information.
} 
explain the "Declining Price Anomaly" (or "Afternoon Effect"). ${ }^{86}$ An early example is McAfee and Vincent (1993) who pursue the intuitive notion that risk-aversion might drive up early prices by providing an incentive to buy early. Actually, McAfee and Vincent's results are essentially negative; declining prices are not consistent with riskaversion of a plausible kind. Nevertheless, theirs is an important analysis and also provides an interesting example in which bidding functions that are monotonic in value do not exist.

Weber (1983) surveys many of the issues that arise in multi-object auctions, focusing primarily on sequential auctions. Unlike the previously-mentioned papers in this subsection, he discusses the complex problems that arise when bidders desire multiple units; Ortega-Reichert $(1968)^{87}$ had already addressed some of these. ${ }^{88,89}$

\subsection{Efficient Auctions}

A main message of much of the current research on multi-unit auctions is that it is very hard to achieve efficient outcomes. ${ }^{90}$ This is in contrast to the single-unit case, in which Maskin (1992) showed under a broad class of assumptions that an ascending auction is efficient if bidders' private signals are single-dimensional, even with asymmetries among bidders and common-value components to valuations.

A Vickrey auction is efficient in private-value multi-unit contexts, ${ }^{91}$ and Dasgupta

\footnotetext{
${ }^{86}$ In fact Milgrom and Weber (1982c) suggest a resolution of the "anomaly" themselves in their discussion of the 1981 sale of leases on RCA satellite-based telecommunications transponders. For other possible resolutions and analyses based on models in which no buyer demands more than one unit, see Bernhardt and Scoones (1994), Engelbrecht-Wiggans (1994), von der Fehr (1994), Gale and Hausch (1994), Beggs and Graddy (1997), and Ginsburg (1998). For analyses when bidders have multi-unit demand see several of the papers cited in note 88 .

${ }^{87}$ Discussed in Weber's paper and in our Section 2, and reprinted in that Part of The Economic Theory of Auctions.

${ }^{88}$ Other nice papers analysing sequential auctions when bidders have multi-unit demand include Robert's ( $\approx 1995)$ very elegant, tractable example; Pitchik and Schotter's (1988), Pitchik's (1995), and Benoit and Krishna's (1998) analyses of budget-constrained bidders; Levin's (1997), Gale, Hausch and Stegeman's (1998), and von der Fehr and Riis's (1999) models of procurement auctions where bidders have increasing or decreasing marginal costs of supply, or capacity constraints, and the related analyses of Black and de Meza (1992), and Gale and Stegeman (1995); Krishna's (1993) application to whether incumbents will outbid potential entrants for capacity; and Hausch's (1986) analysis of sequential versus simultaneous sales in a model with some similarities to Ortega-Reichert's.

${ }^{89}$ McAfee and Vincent (1997) consider an auctioneer who cannot commit not to re-auction an object that fails to meet its reserve, so who might hold multiple auctions of a single unit.

${ }^{90}$ This is true even in the complete information case. See Bikhchandani (1999).

${ }^{91}$ Although even in this context the Vickrey auction would be problematic for practical policy because high-valuers are often required to pay less than low-valuers (which seems odd to policy makers), because of the odd opportunities for collusive behaviour, because of budget constraints, etc.
} 
and Maskin (1998) and Perry and Reny (1998) show how to generalize the Vickrey mechanism to achieve efficiency in a wide variety of multi-unit contexts if each bidder's signal is one-dimensional. But Jehiel and Moldovanu (1998) obtain impossibility results showing that efficiency is not usually possible when each bidder's information signal is multidimensional, as is natural when there are multiple heterogeneous goods.

Ausubel (1998) and Ausubel and Cramton (1998) emphasise the inefficiencies of standard auctions even in the sale of homogeneous objects. In particular, an ascending multi-unit auction (where the sale price equals the first price at which the number of units demanded falls to the supply available) gives a large bidder an incentive to reduce her demand early in order to pay less for those units she does win. ${ }^{92}$

\section{Royalties, Incentives Contracts, and Payments for Quality}

It is usually assumed that bidders' payments can depend only on the bids. But if the winner's value can be observed ex-post, even imperfectly, the seller can do better by making the winner's payment depend on this observation. This removes some of the winner's information rent, and can be interpreted as an application of the Linkage Principle.

Riley (1988) makes this point in a general context. As a practical application, the quantity of oil extracted may be a noisy signal of an oilfield's profitability; Riley shows that the seller's expected revenue can then be increased either by setting perunit royalties that the winner must pay in addition to the fee bid, or by having bidders bid on the royalty rate they are willing to pay rather than on fixed fees. ${ }^{93,94}$

Similarly, Laffont and Tirole (1987) analyze a procurement auction in which the winner will subsequently invest in unobserved effort to reduce its cost. The auctioneer observes the final realised cost. Auctioning an incentive contract with a cost-sharing provision gets a better price for the auctioneer by reducing the difference between

\footnotetext{
${ }^{92}$ Of course, the same effect is present in other models, for example, Klemperer and Meyer (1989).

${ }^{93}$ In analysing this application, he builds on work by Reece (1979).

${ }^{94}$ But note royalties can be very dangerous in some settings. Imagine a government awarding a monopoly license for a market with downward-sloping demand to the firm that will pay the highest royalty per unit sold. Then firms with identical, constant, marginal costs will bid the royalty up to the vertical intercept of demand less this marginal cost. Government revenue, firm profits, and consumer surplus will all be zero. Riley assumes constant per unit revenue from the oil, and decreasing marginal cost up to some output level about which the bidders have private information.
} 
firms' valuations of winning, so reducing the winner's rent (just like a royalty), even though it weakens the incentives for effort to reduce costs. One of Laffont and Tirole's key results is a "separation property": the optimal contract, and hence the winner's final cost, is similar to that which would apply if there were only a single firm and so no bidding competition, while the auction awards the contract to the firm that announces the lowest expected cost. ${ }^{95}$

Che (1993) uses a version of Laffont and Tirole's model to analyse a multidimensional auction in which firms bid on both quality and price in a procurement auction. The auctioneer uses a scoring rule to evaluate the bids. It is no surprise that a revenue equivalence result applies, for example, between "first-score" and "second-score" auctions. Che also shows that it is optimal for the auctioneer to precommit to a scoring rule that underrewards quality relative to her real (ex-post) preferences. ${ }^{96}$ Note that although this is a very elegant model of multidimensional bidding, firms only differ according to a one-dimensional type. ${ }^{97}$

\section{Double Auctions, etc}

\subsection{Double Auctions}

Standard auction theory assumes a single seller who controls the trading mechanism, and many buyers who submit bids. In a double auction, buyers and sellers are treated symmetrically with buyers submitting bids and sellers submitting asks. The double-auction literature thus provides a link to the bargaining literature. We emphasise here models that are closely related to simple, static, standard (one-sided) auctions. $^{98}$

The seminal model is the $k$-Double Auction of Chatterjee and Samuelson (1983) in which a single buyer and single seller submit a bid $b$ and ask $s$, respectively, and if the bid exceeds the ask a trade is consummated at the price $k b+(1-k) s$, where $0 \leq k \leq 1$. Of course, both buyer and seller have incentive to misrepresent their true values, so trades that would be efficient are not necessarily made.

\footnotetext{
${ }^{95}$ The same result is obtained independently in similar models due to McAfee and McMillan (1987d) and Riordan and Sappington (1987). A precursor to this work is McAfee and McMillan (1986).

${ }^{96}$ In terms of the formal model, "quality" plays the role of the bidder's expected cost in Laffont and Tirole. Hence this result.

${ }^{97}$ See also Branco (1997) on multi-dimensional auctions.

${ }^{98}$ Furthermore, all the papers discussed in this Section are independent private-value models. The assumption of private values, especially, seems important.
} 
Wilson (1985) first studied the generalisation to the multi-buyer/multi-seller case in which each agent can trade at most one indivisible unit and, given the bids and asks, the maximum number of feasible trades are made at a price a fraction $k$ of the distance between the lowest and highest feasible market clearing prices. The key result is that a double auction is efficient, in the sense that with sufficiently many buyers and sellers there is no other trading rule for which, conditional on agents' values it is common knowledge that all agents would be better off in expectation.

Rustichini, Satterthwaite and Williams (1994) pursue the question of the extent to which agents' equilibrium bids and asks misrepresent their actual values. The answer is that in large markets the maximum misrepresentation is small, and hence the extent of the inefficiency caused by strategic behavior is also small. ${ }^{99}$

Some intuition is provided by McAfee (1989) who considers the following simple mechanism: if $N$ trades are feasible, let the $(N-1)$ highest value buyers buy at the $N^{\text {th }}$ highest buyer's value while the $(N-1)$ lowest value sellers sell at the $N^{\text {th }}$ lowest seller's value. Now, just as in a second-price auction, all agents report their actual values as dominant strategies, and only the least valuable feasible trade is foregone, and the mechanism also makes money. The fact that this mechanism is obviously so efficient (and McAfee shows how a slightly more complicated scheme does even better) makes it less surprising that other double auction mechanisms are also very efficient.

\subsection{Related Two-Sided Trading Mechanisms}

Related important work includes Myerson and Satterthwaite's (1983) path-breaking general analysis of mechanism design for bilateral trading. They use techniques similar to those of Myerson (1981), and the reader is similarly urged to study the reinterpretation in terms of marginal revenues and marginal costs given in Bulow and Roberts (1989). ${ }^{100}$ Myerson and Satterthwaite show that the symmetric version $\left(k=\frac{1}{2}\right)$ of Chatterjee and Samuelson's two-player double auction is in fact an optimal mechanism, in that it maximises the expected gains from trade, in the case that the agents' values are independently drawn from identical uniform distributions. ${ }^{101}$

\footnotetext{
${ }^{99}$ Satterthwaite and Williams (1989a) and Williams (1991) had earlier obtained similar results for the special case $k=1$ (the "buyer's bid double auction") which is much easier to handle because sellers all have a dominant strategy of no misrepresentation.

${ }^{100}$ These two papers are both discussed in Section 4 and reprinted in the corresponding Part of The Economic Theory of Auctions.

${ }^{101}$ But this result depends critically on the distributional assumptions, and also assumes agents play
} 
This result demonstrates that ex-post efficiency cannot be achieved in bargaining between a seller who initially owns the asset and a buyer with no prior ownership, when there is private information about valuations. However, Cramton, Gibbons and Klemperer (1987) show that ex-post efficiency can be guaranteed (that is, is consistent with incentive compatibility and individual rationality) when the asset to be traded is jointly owned: the reason is that traders' incentives to misrepresent their values are reduced by their uncertainty about whether they will be buyers or sellers. Cramton, Gibbons and Klemperer exhibit one bidding game that achieves efficiency; revenue equivalence means that other auction forms can achieve the same outcome. ${ }^{102}$ This paper explains why ex-post efficient collusion in an auction (that is, efficiently dividing the joint spoils by designating a winner and making appropriate side payments) is possible (see Section 9).

\section{Other Topics}

\subsection{Budget Constraints}

An important reason why revenue equivalence may fail in practice is that bidders may face budget constraints. To see why, consider the standard model in which revenue equivalence applies and bidders have independent private values $v_{i}$, but let bidder $i$ have budget constraint $b_{i}$. Then in a second-price auction $i$ bids exactly as if she had value $x_{i}=\min \left(b_{i}, v_{i}\right)$ but no budget constraint, so by the revenue equivalence theorem ${ }^{103}$ the expected revenue equals that from a first-price auction in which bidders have values $x_{i}$ and no budget constraints, or equivalently a first-price auction in which bidders have values $x_{i}$ and budget constraints $x_{i}$. It is intuitive that this is less expected revenue than from a first-price auction in which bidders have values $v_{i}\left(\geq x_{i}\right)$ and budget constraints $b_{i}\left(\geq x_{i}\right)$. So first-price auctions are more profitable than secondprice auctions. This and similar results are obtained in Che and Gale (1998).

It is also intuitive that auction forms that take payments from losers, such as lotteries and "all-pay" auctions, can be more profitable still in the presence of budget

the linear equilibrium constructed by Chatterjee and Samuelson. There are also non-linear equilibria (see Leininger, Linhart and Radner (1989), and Satterthwaite and Williams (1989b)).

${ }^{102}$ This paper, too, can be understood along the same lines that Bulow and Roberts explain Myerson and Satterthwaite.

${ }^{103} \mathrm{We}$ assume the $b_{i}$ are independently drawn from a strictly increasing atomless distribution, so that the $x_{i}$ correspond to independent draws from a strictly increasing atomless distribution. 
constraints. ${ }^{104}$ Budget constraints are also very important in sequential multi-unit auctions, where they provide incentives to, for example, try to reduce opponents' budgets in early sales in order to lower subsequent sale prices. This is the subject of an important paper in the literature on experimental auctions, Pitchik and Schotter (1988), and is also an area of active research. ${ }^{105}$

\subsection{Externalities between Bidders}

Jehiel and Moldovanu (1996) make an important extension to the theory by incorporating the possibility that a potential buyer cares who buys the object for sale in the event that she does not. This might be the case, for example, when a patent is auctioned to oligopolistic competitors, or when selling nuclear weapons. ${ }^{106}$ Jehiel and Moldovanu's paper raises many of the issues, including demonstrating in the context of first-price auctions with complete information that there may be multiple equilibria, and hence that a potential bidder may do better to avoid an auction rather than show up and risk galvanising an enemy to win. Jehiel, Moldovanu and Stacchetti (1996) address the issue of constructing optimal mechanisms, and Caillaud and Jehiel (forthcoming) show that externalities between bidders tend to make collusion harder.

\subsection{Jump Bidding}

An ascending auction is usually modelled as a continuous process in which each successive bid is an arbitrarily small increment above the previous bid. However, actual behaviour in, for example, takeover battles, often involves "jump bidding" in which a bidder raises the price very substantially with a single bid. ${ }^{107}$

To understand why this might happen, consider a standard independent privatevalue English auction with two symmetric players. The following behaviour is an equilibrium: one player bids the price she would bid in a first-price sealed-bid auction; the second player than infers the first player's actual value and bids that actual value if her own value is higher, but quits the auction otherwise. ${ }^{108}$ So the player with the

\footnotetext{
${ }^{104}$ See Che and Gale (1996).

${ }^{105}$ See Pitchik (1995), Benoit and Krishna (1998) and Harford (1998).

${ }^{106}$ Or an empire. See note 21.

${ }^{107}$ The auction of the Empire (see note 21) was settled by a final jump bid from 5,000 drachms to 6,250 drachms, though in this case bidders' strategies were probably not optimal ex-ante (and certainly not ex-post).

${ }^{108}$ To my knowledge Daniel and Hirshleifer were the first to note that this kind of jump bidding is
} 
actual higher value wins, but the first player pays the first-price auction price when she wins, while the second player pays the second-highest valuation when she wins. Since the higher-value bidder always wins, the outcome is revenue-equivalent to that of the standard continuously ascending model in which the winner always pays the second-highest valuation. And since the first bidder may fear that the second may misunderstand the equilibrium and bid up the price when she will anyway lose, it is not the most natural equilibrium in the simple independent private-value model. But with affiliation, bidders prefer first-price sealed-bid auctions to continuous ascending auctions, as shown in Milgrom and Weber (1982a) ${ }^{109}$, so the first-price features of this equilibrium are attractive to bidders, and Avery (1998) demonstrates that we may therefore expect a "jumping" equilibrium to be played.

If there are costs to making each bid, then jump bidding arises for similar reasons, even with independent private values, see Daniel and Hirshleifer (1995). ${ }^{110}$

\subsection{The War of Attrition}

The War of Attrition is no more than a special kind of auction in which all the bidders pay, and keep on paying at some specified rate, until they quit competing for the prize. (It is irrelevant to the analysis that in most practical contexts the payments are social waste, rather than collected by an auctioneer.) Important early contributions were made by Riley (1980), Bliss and Nalebuff (1984), and Fudenberg and Tirole (1986), among others. Bulow and Klemperer (1999a) extends the analysis to the many-player case, and makes the auction-theoretic underpinnings most explicit, including several appeals to revenue equivalence arguments. ${ }^{111,112}$

\subsection{Competing Auctioneers}

McAfee (1993) examines a model in which many sellers compete for buyers. In equilibrium, in an infinitely large market, each seller holds an efficient auction includ-

an equilibrium of the basic model even absent affiliation or bidding costs.

${ }^{109}$ Discussed in Section 6 and reprinted in that Part of The Economic Theory of Auctions.

${ }^{110}$ Other important papers focusing on second-price auctions include Bikhchandani and Riley (1991) and Rothkopf, Teisberg, and Kahn (1990).

${ }^{111}$ Krishna and Morgan (1997) analyse an open-loop War of Attrition (that is, bidders cannot revise their strategies based on others' drop-out times) and also analyse the closely related All-Pay Auction. ${ }^{112}$ Many other models of tournaments, lobbying, political contests, R\&D races, etc., can most easily be understood as auctions. 
ing setting an efficient reserve price. Thus McAfee and ensuing papers endogenise the use of auctions, and so address the question of when we should expect auctions to arise. $^{113}$

\section{Testing the Theory}

This paper and its companion book is concerned with the theory of auctions, but it would be remiss to exclude any discussion of how well it is supported by data. The Economic Theory of Auctions therefore concludes with two recent surveys, one of the empirical evidence, Laffont $(1997)^{114}$, and one of the experimental evidence, Kagel (1995).

\section{Conclusion}

Auction theory has been among the most successful branches of economics in recent years. The theory has developed rapidly, and is increasingly being looked to for assistance in practical applications. Testing auction-theoretic models is seen as one of the brightest spots in applied economics. Much research remains to be done, especially perhaps on multi-unit auctions, and much research is currently being done. But the foundations of the subject, as presented in many of the papers described here, seem secure.

\footnotetext{
${ }^{113}$ See Peters and Severinov (1997) and Burguet and Sákovics (1999) for further developments along McAfee's lines. In related veins, Manelli and Vincent (1995) study when a procurement auction is more desirable than sequential negotiation, if potential suppliers are privately informed about their goods' qualities; and Bulow and Klemperer (1996) show a standard auction with a reserve price at the auctioneer's value is more profitable than any negotiating mechanism (or optimal auction) if the standard auction attracts at least one more participant (see Section 8.2).

${ }^{114}$ A good alternative is Hendricks and Paarsch (1995), while Porter (1995) and Laffont and Vuong (1996) offer valuable surveys covering a more limited range. Among the outstanding research articles are Hendricks and Porter (1988), and Laffont, Ossard and Vuong (1995).
} 


\section{Appendix A: The Revenue Equivalence Theorem}

For simplicity, we focus on the basic "independent private values" model, in which $n$ bidders compete for a single unit. Bidder $i$ values the unit at $v_{i}$, which is private information to her, but it is common knowledge that each $v_{i}$ is independently drawn from the same continuous distribution $F(v)$ on $[\underline{v}, \bar{v}]($ so $F(\underline{v})=0, F(\bar{v})=1)$ with density $f(v)$. All bidders are risk-neutral.

Consider any mechanism (any single-stage or multi-stage game) for allocating the unit among the $n$ bidders. For this mechanism, and for a given bidder $i$, let $S_{i}(v)$ be the expected surplus that bidder $i$ will obtain in equilibrium from participating in the mechanism, as a function of her type, which we now denote by $v$, rather than $v_{i}$, for notational convenience. Let $P_{i}(v)$ be her probability of receiving the object in the equilibrium.

The following equation is the key:

$$
S_{i}(v) \geq S_{i}(\widetilde{v})+(v-\widetilde{v}) P_{i}(\widetilde{v})
$$

The right-hand side is the surplus that player $i$ would obtain if she had type $v$ but

deviated from equilibrium behaviour, and instead followed the strategy that type $\widetilde{v}$ of player $i$ is supposed to follow in the equilibrium of the game induced by the mechanism. That is, if type $v$ exactly mimics what type $\widetilde{v}$ would do, then $v$ makes the same payments and wins the object as often as $\widetilde{v}$ would. So $v$ gets the same utility that $\widetilde{v}$ would get $\left(S_{i}(\widetilde{v})\right)$, except that in states in which $\widetilde{v}$ would win the object (which happens with probability $\left.P_{i}(\widetilde{v})\right)$ type $v$ values the object at $(v-\widetilde{v})$ more than $\widetilde{v}$ does, and so $v$ obtains an extra $(v-\widetilde{v}) P_{i}(\widetilde{v})$ more surplus in all. In an equilibrium, $v$ must prefer not to deviate from equilibrium behaviour, so the left-hand side must (weakly) exceed the right-hand side.

So, since type $v$ mustn't want to mimic type $v+d v$, we have

$$
S_{i}(v) \geq S_{i}(v+d v)+(-d v) P_{i}(v+d v)
$$

(this is just (1) with $\widetilde{v}$ substituted by $v+d v$ ), and since $v+d v$ mustn't want to mimic type $v$ we have

$$
S_{i}(v+d v) \geq S_{i}(v)+(d v) P_{i}(v) .
$$


Reorganising (2) and (3) yields

$$
P_{i}(v+d v) \geq \frac{S_{i}(v+d v)-S_{i}(v)}{d v} \geq P_{i}(v)
$$

and taking the limit as $d v \rightarrow 0$ we obtain ${ }^{115}$

$$
\frac{d S_{i}}{d v}=P_{i}(v) .
$$

Integrating up,

$$
S_{i}(v)=S_{i}(\underline{v})+\int_{x=\underline{v}}^{v} P_{i}(x) d x .
$$

Equation (5) gives us a picture like Figure 1.

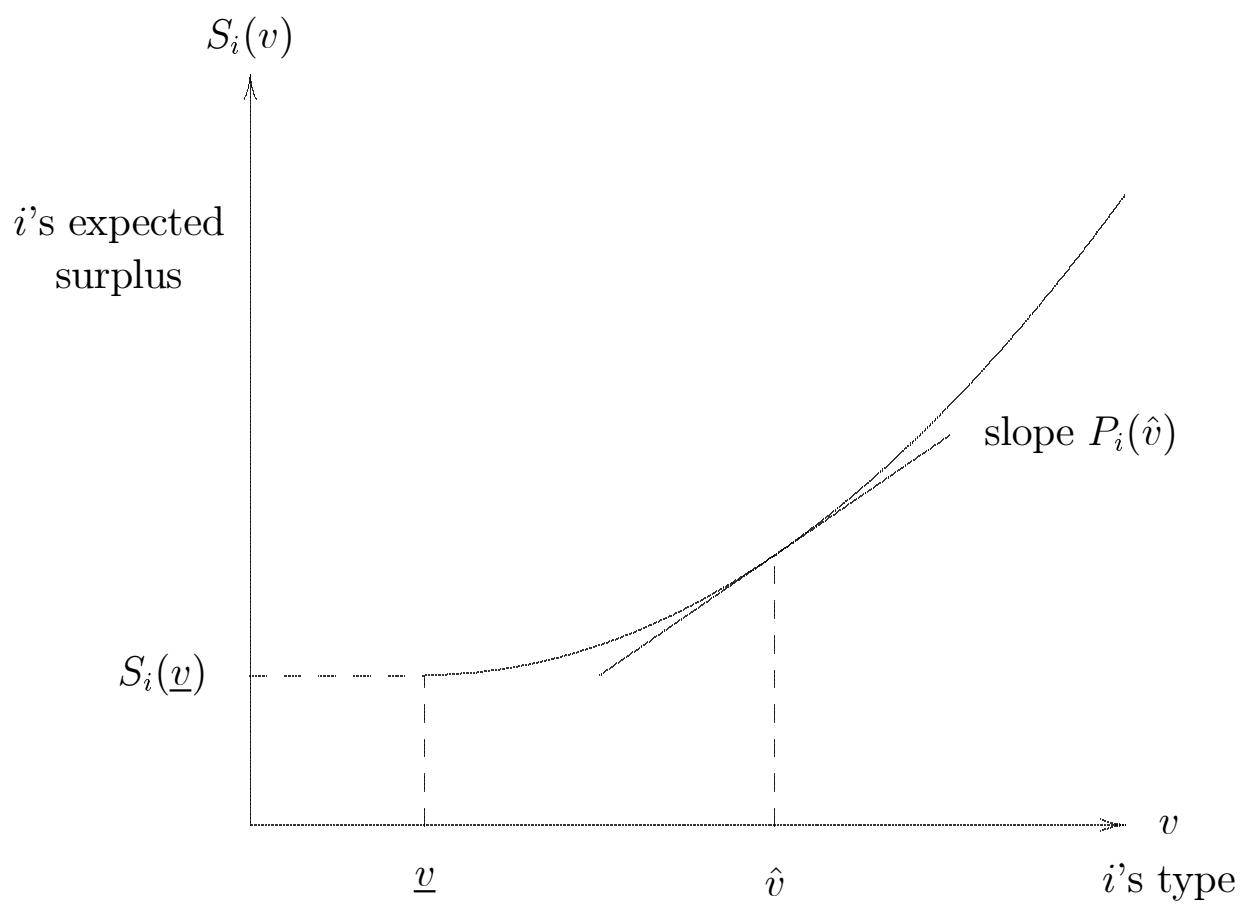

Figure 1: Bidder $i$ 's expected surplus as a function of her type.

At any type $\widehat{v}$ the slope of the surplus function is $P_{i}(\widehat{v})$, so if we know where the surplus function starts (that is, know $S_{i}(\underline{v})$ ) we know the entire picture.

Now consider any two mechanisms which have the same $S_{i}(\underline{v})$ and the same $P_{i}(v)$ functions for all $v$ and for every player $i$. They have the same $S_{i}(v)$ functions. So

\footnotetext{
${ }^{115}$ An alternative way of obtaining this equation is to write $S_{i}(v)=T(v, \widetilde{v}(v))$ equals $v$ 's surplus when she behaves optimally as type $\widetilde{v}(v)$. (In fact, $\widetilde{v}(v)=v$.) Then the envelope theorem implies $\frac{d S_{i}}{d v}=\frac{d T}{d v}=\frac{\partial T}{\partial v}$. (That is, $\frac{d T}{d v}=\frac{\partial T}{\partial v}+\frac{\partial T}{\partial \widetilde{v}} \frac{d \widetilde{v}}{d v}$ but $\frac{\partial T}{\partial \widetilde{v}}=0$ when $\widetilde{v}$ is chosen optimally.)

But $\frac{\partial T}{\partial v}=P_{i}(v)$, since if the bidder's behaviour is unchanged, the incremental utility from a value $d v$ higher is $P_{i}(v) d v$.
} 
any given type, $v$, of player $i$ makes the same expected payment in each of the two mechanisms (since $S_{i}(v)=v P_{i}(v)-E$ (payment by type $v$ of player $i$ ), since the bidder is risk-neutral). So $i$ 's expected payment averaged across her different possible types, $v$, is also the same for both mechanisms. Since this is true for all bidders, $i$, the mechanisms yield the same expected revenue for the auctioneer. ${ }^{116}$

This is the Revenue Equivalence Theorem. There are many different statements of it, but they all essentially give the results of the preceding paragraph in a more or less special form.

In particular any mechanism which always gives the object to the highest-value bidder in equilibrium (all the standard auction forms do this) has $P_{i}(v)=(F(v))^{n-1}$ (since a bidder's probability of winning is just the probability that all the other $(n-1)$ bidders have lower values then she does), and many mechanisms (including all the standard ones) give a bidder of the lowest feasible type no chance of any surplus, that is, $S_{i}(\underline{v})=0$, so all these mechanisms will yield the same expected payment by each bidder and the same expected revenue for the auctioneer.

Notice that nothing about this argument (except the actual value of $P_{i}(v)$ ) relied on there being only a single object. Thus the theorem extends immediately to the case of $k>1$ indivisible objects being sold, provided bidders want no more than one object each; all mechanisms that give the objects to the $k$ highest-value bidders are revenue-equivalent. So we have:

Revenue Equivalence Theorem (Private-Value Case) Assume each of $n$ riskneutral potential buyers has a privately-known value independently drawn from a common distribution $F(v)$ that is strictly increasing and atomless on $[\underline{v}, \bar{v}]$. No buyer wants more than one of the $k$ available identical indivisible objects. Any auction mechanism in which (i) the objects always go to the $k$ buyers with the highest values, and (ii) any bidder with value $\underline{v}$ expects zero surplus, yields the same expected revenue, and results

\footnotetext{
${ }^{116}$ Some readers may wish to think of this analysis in terms of the Revelation Principle (see Myerson (1979), Dasgupta, Hammond, and Maskin (1979), and Harris and Townsend (1981)) that says that we can always restrict attention to direct revelation mechanisms that satisfy incentive compatibility. That is, any mechanism is equivalent to another mechanism in which agents report their types, $v$, and wish to do so truthfully. Here we have analysed any auction by focusing attention on the equivalent truthful direct revelation mechanism. In our problem the incentive compatibility (truthtelling) constraints, (1), completely pin down the payments that must be made to each type of agent once $P_{i}(v)$ and $S_{i}(\underline{v})$ have been specified.
} 
in a buyer with value $v$ making the same expected payment.

It is not hard to extend the result to the general (common- and/or private-value) case, in which each buyer, $i$, independently receives a signal $t_{i}$ drawn from $[\underline{t}, \bar{t}]$ and each bidder's value $V_{i}\left(t_{1}, \ldots, t_{n}\right)$ depends on all the signals. ${ }^{117}$ A more general statement of the theorem is then the statement above, but with "signal" substituted for "value", and $t, \underline{t}$, and $\bar{t}$ substituted for $v, \underline{v}$, and $\bar{v}$, throughout.

\section{Application to Computing Bidding Strategies}

Again we focus, for simplicity, on the single-object private-value case.

One of the mechanisms satisfying the Revenue Equivalence Theorem is the ascending auction, in which the expected payment of a bidder of type $v$ is just $P_{i}(v)$ times the expectation of the highest of the remaining $(n-1)$ values conditional on all these values being below $v$. Since the density of the highest of $(n-1)$ values is $(n-1) f(v)(F(v))^{n-2}$, this last expectation can be written as

$$
\frac{\int_{x=\underline{v}}^{v} x(n-1) f(x)(F(x))^{n-2} d x}{\int_{x=\underline{v}}^{v}(n-1) f(x)(F(x))^{n-2} d x}
$$

which, after integrating the numerator by parts, ${ }^{118}$ yields

$$
v-\frac{\int_{x=\underline{v}}^{v}(F(x))^{n-1} d x}{(F(v))^{n-1}} .
$$

Since in a first-price sealed-bid auction, $v$ 's expected payments are $P_{i}(v)$ times her bid, it follows that $v$ bids according to

$$
b(v)=v-\frac{\int_{x=\underline{v}}^{v}(F(x))^{n-1} d x}{(F(v))^{n-1}}
$$

in a first-price auction.

In an "all-pay" auction in which every competitor always pays her bid (but only the highest-payer wins the object), it likewise follows that $v$ must bid

$$
b(v)=(F(v))^{n-1} v-\int_{x=\underline{v}}^{v}(F(x))^{n-1} d x .
$$

\footnotetext{
${ }^{117}$ See, for example, Lemma 3 of Bulow and Klemperer (1996) (reprinted in Part 8 of The Economic Theory of Auctions).

${ }^{118}$ The denominator integrates to $(F(v))^{n-1}$, and the numerator $\int_{x=\underline{v}}^{v} x\left[(n-1) f(x)(F(x))^{n-2}\right] d x=$ $\int_{x=\underline{v}}^{v} x d\left(F(x)^{n-1}\right)=\left[x \cdot(F(x))^{n-1}\right]_{\underline{v}}^{v}-\int_{x=\underline{v}}^{v} 1 .(F(x))^{n-1} d x$, which yields the result.
} 
Computing the bidding strategies this way is somewhat easier than solving for them directly in these cases. ${ }^{119,120}$ In other cases, see, for example, Bulow and Klemperer $(1994)^{121}$ it is very much easier. ${ }^{122}$

${ }^{119}$ Appendix D illustrates for the case in which $F(\cdot)$ is uniform.

${ }^{120}$ To solve directly for the first-price equilibrium bidding strategies, we look for a symmetric Nash equilibrium in which a bidder with value $v$ chooses the bid $b(v)$, and assume (as can be proved, see, for example, Example 6.5 of Fudenberg and Tirole (1991)) that $b$ is a continuous strictly-increasing function of $v$. Imagine player $i$ with value $v$ deviates and chooses the bid $\widetilde{b}$. Let $\widetilde{v}$ be the type of bidder she would just tie with, that is, let $b(\widetilde{v})=\widetilde{b}$. Mimicking $\widetilde{v}$ would beat all the other $(n-1)$ bidders with probability $(F(\widetilde{v}))^{n-1}$ and so yield expected surplus to player $i$ of

$$
T(v, \widetilde{v})=(v-b(\widetilde{v}))(F(\widetilde{v}))^{n-1} .
$$

Choosing the best bid to make is equivalent to choosing the best $\widetilde{v}$ to mimic, which we can do by looking at the first-order condition

$$
\frac{\partial T(v, \widetilde{v})}{\partial \widetilde{v}}=-b^{\prime}(\widetilde{v})(F(\widetilde{v}))^{n-1}+(v-b(\widetilde{v}))(n-1)(F(\widetilde{v}))^{n-2} f(\widetilde{v}) .
$$

For the bidding function $b(v)$ to be an equilibrium, $i$ 's best-response to all others bidding according to this function must be to do likewise, that is, her optimal choice of $\widetilde{b}$ is $b(v)$ and of $\widetilde{v}$ is $v$.

So

$$
\begin{gathered}
\frac{\partial T}{\partial \widetilde{v}}(v, \widetilde{v})=0 \text { at } \widetilde{v}=v \\
\Rightarrow \quad b^{\prime}(v)=(v-b(v))(n-1) \frac{f(v)}{F(v)} .
\end{gathered}
$$

This differential equation can be solved for the equilibrium, using the boundary condition

$$
b(\underline{v})=\underline{v}
$$

(it is obvious type $\underline{v}$ will not bid more than $\underline{v}$, and we assume the auctioneer will not accept lower bids than $\underline{v}$ ).

${ }^{121}$ Described in Section 10 and reprinted in that Part of The Economic Theory of Auctions.

${ }^{122}$ For an example of using the revenue equivalence theorem to solve an oligopoly pricing problem, see Appendix B of Bulow and Klemperer (1999b). 


\section{Appendix B: Marginal Revenues}

This Appendix develops the basics of the "marginal revenue" approach to auctions.

We begin by following Bulow and Klemperer (1996) ${ }^{123}$ to show, very generally, that the expected revenue from an ascending auction equals the expected marginal revenue of the winning bidder.

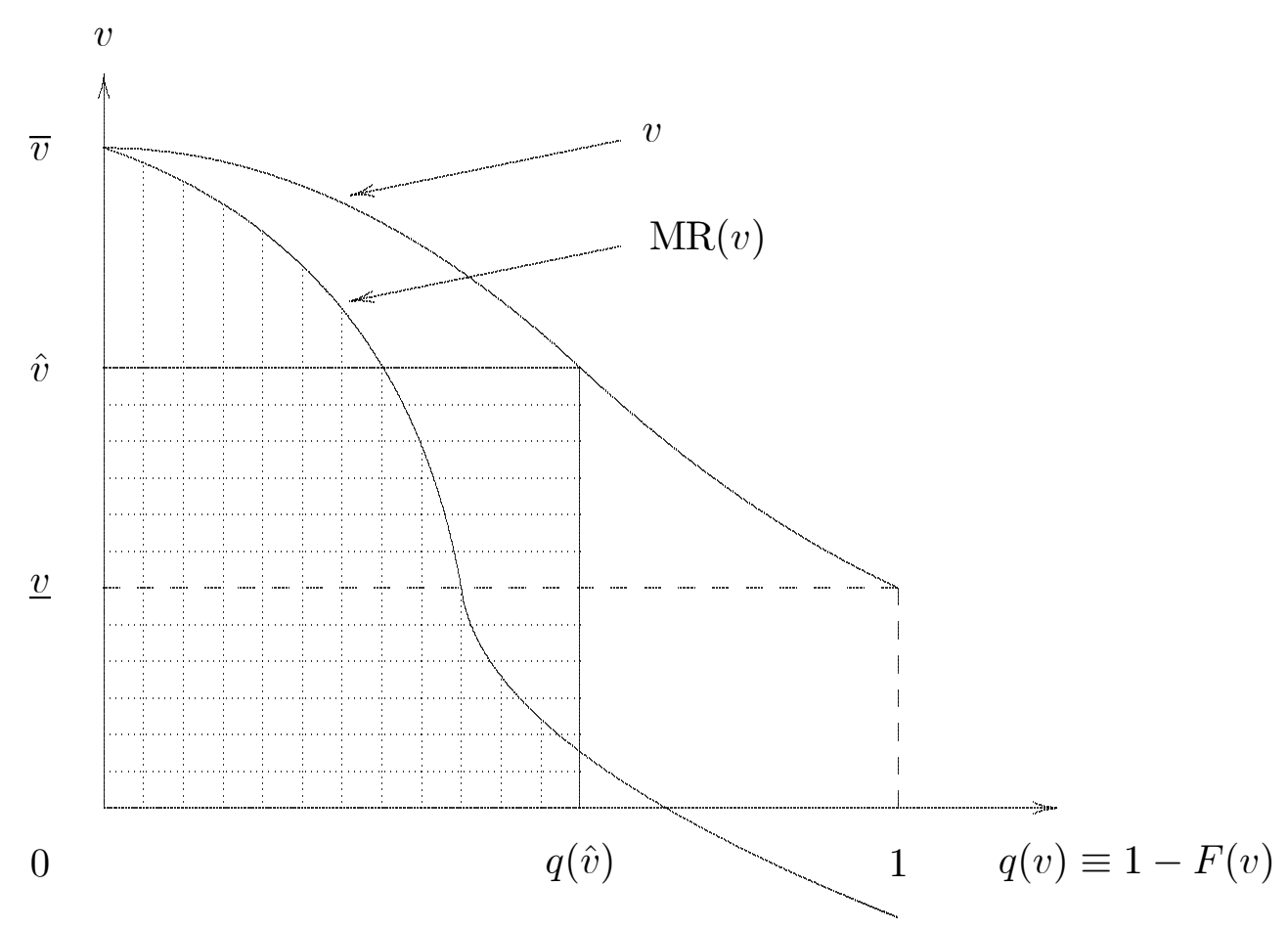

Figure 2: "Demand" and "Marginal Revenue" curves for bidder with value, $v$, drawn from $F(v)$.

Figure 2 plots value, $v$, against $1-F(v)$ for bidder $i$. We can interpret this as a "demand curve" because bidder $i$ 's value exceeds any $v$ with probability $1-F(v)$, so if a monopolist faced the single bidder, $i$, and set a take-it-or-leave-it offer of price $\widehat{v}$, the monopolist would make a sale with probability $1-F(\widehat{v})$, that is, the monopolist's expected quantity of sales would be $q(\widehat{v})=1-F(\widehat{v})$.

Figure 2 also shows a "marginal revenue curve", $M R(v)$, constructed from the ${ }^{123}$ Also discussed in Section 8.2, and reprinted in that Part of The Economic Theory of Auctions. 
demand curve in exactly the usual way. ${ }^{124}$ Note that at "price" $\widehat{v}$ the monopolist's expected revenues can be computed either as the horizontally-shaded rectangle $\widehat{v} \cdot[1-F(\widehat{v})]$, or as the vertically-shaded area under the "marginal revenue" curve $M R(v)$ up to "quantity" $1-F(\widehat{v})$. That is, just as in standard monopoly theory, the monopolist's revenues can be computed either as price times quantity, or as the sum of the marginal revenues of all the units sold. (Mathematically, we can write $\left.\widehat{v} \cdot[q(\widehat{v})]=\int_{q=0}^{q(\widehat{v})} M R(v(q)) d q \cdot{ }^{125}\right)$

Now imagine bidder $i$ is the winner of the ascending auction. Let $\widehat{v}$ be the actual value of the second-highest bidder. So the actual price in the auction equals $\widehat{v}$. But the result of the previous paragraph tells us that $\widehat{v}$ equals the average level of the marginal revenue curve between 0 and $q(\widehat{v})$. (Mathematically, we have $\widehat{v}=$ $\left.\frac{1}{q(\widehat{v})} \int_{q=0}^{q(\widehat{v})} M R(v(q)) d q.\right) \quad$ That is, $\widehat{v}$ equals the average value of $i$ 's marginal revenue, conditional on $i$ 's value exceeding $\widehat{v}$. But what we know about $i$ 's value is just that it exceeds $\widehat{v}$, because $i$ won the auction. So for any actual second-highest value $\widehat{v}$, the price, and hence the actual revenue, equals the expected marginal revenue of the winner. So the expected revenue from an ascending auction equals the expected marginal revenue of the winning bidder.

Observe that the result is very general for ascending auctions. Nothing in the argument relies on bidders' private values being independent, nor on bidders being risk-neutral, nor on their values being drawn from a common distribution. It is also not hard to check that the argument extends directly to the general (common- and/or private- value) case. (See Bulow and Klemperer (1996) for full details.)

Obviously the result also extends to any auction that is revenue equivalent to the ascending auction. Noting the conditions for revenue equivalence (see Appendix A) it follows that ${ }^{126}$ if the bidders are risk-neutral and their information signals are independent, the expected revenue from any standard auction equals the expected marginal

${ }^{124}$ That is, "revenue" = "price" times "quantity" $=v \cdot q(v)$, so

$$
M R(v)=\frac{d}{d q}[v \cdot q(v)]=v+\frac{q}{d q / d v}=v-\frac{1-F(v)}{f(v)}
$$

${ }^{125}$ We can confirm $\int_{q=0}^{q(\widehat{v})} M R(v(q)) d q=\int_{v=\widehat{v}}^{\bar{v}} M R(v) f(v) d v$ (changing variables $q \rightarrow[1-F(v)], d q \rightarrow$ $[-f(v) d v]$, reversing limits to cancel the minus sign and defining $q(\bar{v})=0$ as in Appendix A) $=$ $\int_{v \bar{v} \widehat{v}}^{\bar{v}}(v f(v)-1+F(v)) d v=[v F(v)-v]_{v=\widehat{v}}^{\bar{v}}=\widehat{v}-\widehat{v} F(\widehat{v})$ as claimed.

${ }^{1 \overline{2}{ }^{2}}$ It is not hard to check that bidders can be asymmetric, that is, their signals can be drawn from different distributions. 
revenue of the winning bidder.

\section{Alternative, Algebraic, Proof}

For the risk-neutral, independent, symmetric, private-value case we can alternatively obtain the result using the results (and notation) of Appendix A: ${ }^{127}$ Bidder $i$ 's expected payment to the auctioneer equals $i$ 's expected gross value received from the auction, $v P_{i}(v)$, less her expected surplus, $S_{i}(v)$. So the auctioneer's expected receipts from $i$ are

$$
\int_{v=\underline{v}}^{\bar{v}}\left(v P_{i}(v)-S_{i}(v)\right) f(v) d v
$$

Substituting for $S_{i}(v)$ using equation (5) from Appendix A yields

$$
\int_{v=\underline{v}}^{\bar{v}} v P_{i}(v) f(v) d v-\int_{v=\underline{v}}^{\bar{v}} f(v) \int_{x=\underline{v}}^{v} P_{i}(x) d x d v-\int_{v=\underline{v}}^{\bar{v}} S_{i}(\underline{v}) f(v) d v,
$$

and integrating the second term by parts ${ }^{128}$ yields

$$
\int_{v=\underline{v}}^{\bar{v}} P_{i}(v) f(v)\left[v-\frac{1-F(v)}{f(v)}\right] d v-S_{i}(\underline{v}) .
$$

Define bidder $i$ 's "marginal revenue" if she has value $v$ to be $M R_{i}(v)=\left[v-\frac{1-F(v)}{f(v)}\right]$; following the discussion of Figure 2, above, this corresponds to thinking of $v$ as "price", $p$, and of $1-F(v)$ as "quantity", $q$, hence marginal revenue $=\frac{d(p q)}{d q}=p+\frac{q}{d q / d p}=$ $v+\frac{1-F(v)}{-f(v)}$. Then, assuming $S_{i}(\underline{v})=0$, as is the case for any standard mechanism (see Appendix A), the auctioneer's receipts from all $n$ bidders are

$$
\sum_{i=1}^{n} \int_{v=\underline{v}}^{\bar{v}} P_{i}(v) f(v) M R_{i}(v) d v .
$$

This expression equals the expected marginal revenue of the winning bidder. To see this, it is helpful to write $\widetilde{P}_{i}\left(v_{1}, \ldots, v_{n}\right)$ as the probability that $i$ wins as a function of all bidders' signals (that is, $\widetilde{P}_{i}\left(v_{1}, \ldots, v_{n}\right)=1$ if $i$ is the winner, $\widetilde{P}_{i}\left(v_{1}, \ldots, v_{n}\right)=0$ otherwise). Then

\footnotetext{
${ }^{127}$ This approach is the one taken by Bulow and Roberts (1989), who themselves follow Myerson (1981).

128 That is,$$
\int_{v=\underline{v}}^{\bar{v}} f(v) \int_{x=\underline{v}}^{v} P_{i}(x) d x d v=\left[F(v) \int_{x=\underline{v}}^{v} P_{i}(x) d x\right]_{v=\underline{v}}^{\bar{v}}-\int_{v=\underline{v}}^{\bar{v}} F(v) P_{i}(v) d v=\int_{v=\underline{v}}^{\bar{v}}(1-F(v)) P_{i}(v) d v
$$ 


$$
\begin{aligned}
P_{i}\left(v_{i}\right)=\int_{v_{1}=\underline{v}}^{\bar{v}} \ldots \int_{v_{i-1}=\underline{v}}^{\bar{v}} & \int_{v_{i+1}=\underline{v}}^{\bar{v}} \ldots \int_{v_{n}=\underline{v}}^{\bar{v}} \widetilde{P}_{i}\left(v_{1}, \ldots, v_{n}\right) f\left(v_{1}\right) \ldots \\
& \ldots f\left(v_{i-1}\right) f\left(v_{i+1}\right) \ldots f\left(v_{n}\right) d v_{1} \ldots d v_{i-1} d v_{i+1} \ldots d v_{n},
\end{aligned}
$$

so expected total receipts can be written

$$
\int_{v_{1}=\underline{v}}^{\bar{v}} \ldots \int_{v_{n}=\underline{v}}^{\bar{v}}\left[\sum_{i=1}^{n} M R_{i}\left(v_{i}\right) \widetilde{P}_{i}\left(v_{1}, \ldots, v_{n}\right)\right] f\left(v_{1}\right) \ldots f\left(v_{n}\right) d v_{1} \ldots d v_{n}
$$

which equals the expected marginal revenue of the winning bidder, since the term in square brackets is exactly the marginal revenue of the winner. If there is no sale for some realization of $v_{1}, \ldots, v_{n}$, then the term in square brackets equals zero, so it is as if there was a winner with marginal revenue equal to zero.

So an auction that always sells to the bidder with the highest marginal revenue, except makes no sale if no bidder's marginal revenue exceeds zero, will maximise expected revenues. But with symmetric bidders, any standard auction will sell to the highest-value bidder. So if higher values imply higher marginal revenues, then any standard auction together with reserve price $p_{r}$ such that $M R\left(p_{r}\right)=0$ (to prevent any sale if all bidders have values below $p_{r}$, hence negative marginal revenues) maximises the auctioneer's expected revenues. ${ }^{129}$

Note also that this approach generalizes easily to bidders drawn from different distributions, and to the general (common and/or private-value) case, but the riskneutrality and independence assumptions are important, as they are for the revenue equivalence theorem.

\footnotetext{
${ }^{129}$ Appendix D illustrates for the case of uniform $F(\cdot)$.

See Myerson (1981) and Bulow and Roberts (1989) for the design of revenue-maximising auctions when bidders are asymmetric or when higher values do not always imply higher marginal revenues.
} 


\section{Appendix C: Affiliated Signals}

This Appendix analyses the relative profitabilities of the standard auction forms when bidders' signals are affiliated. ${ }^{130}$

Loosely, two signals are affiliated if a higher value of one signal makes a higher value of the other signal more likely, and this is true on every subspace of the variables' domain. Thus affiliation is stronger than correlation which is just a global summary statistic; affiliation can be thought of as requiring local positive correlation everywhere.

Milgrom and Weber found that when signals are affiliated, the second-price open (that is, ascending) auction raises more expected revenue than the second-price sealedbid auction, which in turn beats the first-price auction (assuming risk-neutral bidders, whose signals are drawn from symmetric distributions, and whose value functions are symmetric functions of the signals). Why?

Begin with independent-private-value first-price auctions. Recall the intuition for equation (4) from Appendix A,

$$
\frac{d S_{i}(v)}{d v}=P_{i}(v)
$$

that if a player has a value of $v+d v$ instead of $v$, she can emulate the strategy of a player with value $v$ and win just as often, at the same cost, but earning an extra $d v$ in the probability $P_{i}(v)$ event she wins.

Now consider affiliation. A player with a value of $v+d v$ who makes the same bid as a player with a value of $v$ will pay the same price as a player with a value of $v$ when she wins, but because of affiliation she will expect to win a bit less often. That is, her higher signal makes her think her competitors are also likely to have higher signals, which is bad for her expected profits.

But things are even worse in a second-price affiliated private-values auction for the buyer. Not only does her probability of winning diminish, as in the first-price auction, but her costs per victory are higher. This is because affiliation implies that contingent on her winning the auction, the higher her value the higher the expected second-highest value which is the price she has to pay. Because the person with the highest value will win in either type of auction they are both equally efficient, and

\footnotetext{
${ }^{130}$ The first part of this Appendix is based on notes written by Jeremy Bulow. Appendix D provides examples that illustrate the results.
} 
therefore the higher consumer surplus in the first-price auction implies higher seller revenue in the second-price auction. ${ }^{131}$

How about second-price sealed-bid auctions versus ascending auctions? Sticking to private values, these two auction types will still be identical: the highest-valued bidder will always pay the second value. Also, with only two bidders there is no difference between sealed and open bids even with a common-value element and affiliation. In the open auction the player drops out when the price reaches her value for the good, conditional on the other bidder having the same signal as her; ${ }^{132}$ in the sealed-bid version a player bids her value conditional on the other player having the same signal. ${ }^{133}$

If there are more than two bidders in a setting with affiliation and common values, then the ascending auction beats the sealed-bid auction: Assume there are three potential bidders in a second-price sealed-bid auction, each of whom reveals her signal to a trusted fourth party. The fourth party then tells the two most optimistic bidders that they are among the top two, but doesn't reveal the third bidder's signal. The first two will bid exactly as they would have without the information that they are in the top two, since their bids are only relevant in this case anyway. How will each bidder determine her bid? The marginal case in which it would be worthwhile for a bidder to win the auction is the case where she is tied for having the most optimistic signal. The second-highest actual bidder, whose bid determines the price, will bid the expectation of the asset's value, assuming that she is tied for the most optimistic assessment, and assuming there is a third observation with the distribution to be expected if, in fact, the second bidder $i s$ tied for the most optimistic signal. ${ }^{134}$

However, the seller knows that contingent on the second bidder observing any given

\footnotetext{
${ }^{131}$ To fill out this argument a little more, assume that in equilibrium there is some value for which the expected surplus (and therefore expected purchase price) is the same for a buyer in either type of auction. This will be true for the lowest-possible buyer value, for example, since that type of buyer obviously never wins the auction. Then by the argument in the text, the derivative of surplus with respect to value will be greater in the first-price auction than in the second-price auction. So the surplus in the first-price auction begins to grow faster, at least for a while, in the second-price auction. And if the surpluses ever came together again, the first-price surplus would have to forge ahead again. So on average across all possible bidder values, buyers will get more surplus in first-price auctions and sellers will make more money in second-price auctions.

${ }^{132}$ To see why, check that if the other player is bidding this way then this player would lose money if she were to find herself a winner at a higher price (assuming higher signals imply higher values) but quitting at a lower price forgoes an opportunity to make money if the other player quits first.

${ }^{133}$ The argument that the games are strategically equivalent is similar to the one for first-price and descending auctions.

${ }^{134}$ See Appendix D for more discussion and examples.
} 
signal and there existing a first bidder with a more optimistic observation, the true distribution of this unknown third signal is a more optimistic one than the second bidder will use. (For example, given that the top two bidders have values of 30 and 40, the expectation of the third signal is higher than the expectation that the second bidder will use in a sealed-bid auction, which conditions on the top two values being 30 and 30.) Thus, the seller will do better on average to allow the bidder to make her offer contingent on the observation of the third bidder, as in the open auction where the third bidder's observation can be inferred from the price at which she drops out.

So, with affiliation, common-value elements, and more than two symmetric, riskneutral, bidders, the first-price auction earns less revenue on average than the secondprice sealed-bid auction which earns less than the ascending auction. With private values and/or only two bidders, the first-price auction still earns the least money but the other two types are tied.

Appendix D provides some simple examples that illustrate these results.

\section{Formal Definition}

Formally, but still restricting for simplicity to the case of two bidders, signals $t_{1}$ and $t_{2}$ are affiliated if for all $t_{1}^{\prime}>t_{1}^{\prime \prime}$ and $t_{2}^{\prime}>t_{2}^{\prime \prime}$,

$$
f\left(t_{1}^{\prime}, t_{2}^{\prime}\right) f\left(t_{1}^{\prime \prime}, t_{2}^{\prime \prime}\right) \geq f\left(t_{1}^{\prime}, t_{2}^{\prime \prime}\right) f\left(t_{1}^{\prime \prime}, t_{2}^{\prime}\right)
$$

in which $t_{i}^{\prime}$ and $t_{i}^{\prime \prime}$ are different possible realisations of the signals $t_{i}, i=1,2$, and $f\left(t_{1}, t_{2}\right)$ is the joint density function of the signals. Since, by the definition of conditional probability, $f\left(t_{1}, t_{2}\right)=g\left(t_{1} \mid t_{2}\right) h\left(t_{2}\right)$, in which $g\left(t_{1} \mid t_{2}\right)$ and $h\left(t_{2}\right)$ are the conditional density of $t_{1}$ given $t_{2}$, and the unconditional density of $t_{2}$, respectively, it follows that (6) holds if and only if

$$
\frac{g\left(t_{1}^{\prime} \mid t_{2}^{\prime}\right)}{g\left(t_{1}^{\prime \prime} \mid t_{2}^{\prime}\right)} \geq \frac{g\left(t_{1}^{\prime} \mid t_{2}^{\prime \prime}\right)}{g\left(t_{1}^{\prime \prime} \mid t_{2}^{\prime \prime}\right)}
$$

which is also known as the Monotone Likelihood Ratio Property, that is, higher values of $t_{1}$ become relatively more likely as $t_{2}$ increases. An implication of (7) is that ${ }^{135}$

$$
G\left(t_{1} \mid t_{2}^{\prime}\right) \leq G\left(t_{1} \mid t_{2}^{\prime \prime}\right)
$$

\footnotetext{
${ }^{135}$ To obtain this, integrate first over $t_{1}^{\prime}>t_{1}$, then multiply through by $g\left(t_{1}^{\prime \prime} \mid t_{2}^{\prime}\right) g\left(t_{1}^{\prime \prime} \mid t_{2}^{\prime \prime}\right)$, then integrate over $t_{1}^{\prime \prime}<t_{1}^{\prime}$ to yield an expression which implies this one.
} 
in which $G\left(t_{1} \mid t_{2}\right)$ is the conditional distribution of $t_{1}$ given $t_{2}$. In words, the distribution of $t_{1}$ conditional on $t_{2}^{\prime}$ stochastically dominates the distribution of $t_{1}$ conditional on $t_{2}^{\prime \prime}$, if $t_{2}^{\prime}>t_{2}^{\prime \prime}$. The implication of affiliation that is probably used most frequently in auction-theory proofs is that ${ }^{136}$

$$
\frac{\partial}{\partial t_{2}}\left(\frac{g\left(t_{1} \mid t_{2}\right)}{1-G\left(t_{1} \mid t_{2}\right)}\right) \leq 0 .
$$

In words, the hazard rate of $t_{1}$ is everywhere decreasing in $t_{2}$.

In the case of independent signals, affiliation holds weakly.

${ }^{136}$ To obtain this integrate (7) over $t_{1}^{\prime}>t_{1}^{\prime \prime}$, and substitute $t_{1}$ for $t_{1}^{\prime \prime}$. 


\section{Appendix D: Examples Using the Uniform Distri- bution}

This Appendix uses the uniform distribution to develop some simple examples of bidding in the standard auctions, and illustrates the material in the preceding Appendices.

The uniform distribution $\left(F(v)=\frac{v-\underline{v}}{\bar{v}-\underline{v}}, f(v)=\frac{1}{\bar{v}-\underline{v}}\right)$ is often particularly easy to work with in auction theory. The following fact is very helpful: the expected $k^{\text {th }}$ highest value among $n$ values independently drawn from the uniform distribution on $[\bar{v}, \underline{v}]$ is

$$
\underline{v}+\left(\frac{n+1-k}{n+1}\right)(\bar{v}-\underline{v}) .
$$

\section{Bidding with Independent Private Values, Revenue Equivalence, and Marginal Revenues}

Begin with risk-neutral bidders $i=1, \ldots, n$ each of whom has a private value $v_{i}$ independently drawn from $[\underline{v}, \bar{v}]$.

Then in a second-price (or ascending) auction, everyone bids (or bids up to) her true value, so the seller's expected revenue is the expected second-highest value of the $n$ values which, using the fact given above, equals $\underline{v}+\left(\frac{n-1}{n+1}\right)(\bar{v}-\underline{v})$.

In a first-price auction, by revenue equivalence, $i$ bids her expected payment conditional on winning an ascending auction. Conditional on $v_{i}$ being the highest value, the other $n-1$ values are uniformly distributed on $\left[\underline{v}, v_{i}\right]$ so, using the fact about the uniform distribution, the expected value of the highest of these - which is what $i$ would expect to pay conditional on winning - is $\underline{v}+\left(\frac{n-1}{n}\right)\left(v_{i}-\underline{v}\right)$, so this will be $i$ 's bid.

Alternatively, we can derive $i$ 's equilibrium bidding strategy using the direct approach, and thus confirm revenue equivalence. ${ }^{137}$

${ }^{137}$ The differential equation for $i$ 's first-price bidding strategy, $b\left(v_{i}\right)$, obtained using the direct approach, is $b^{\prime}\left(v_{i}\right)=\left(v_{i}-b\left(v_{i}\right)\right)(n-1) \frac{f\left(v_{i}\right)}{F\left(v_{i}\right)}$ (see note 120$)$.

For the uniform distribution, this yields $b^{\prime}\left(v_{i}\right)=\left(v_{i}-b\left(v_{i}\right)\right)(n-1)\left(\frac{1}{v_{i}-\underline{v}}\right)$ which is solved by $b\left(v_{i}\right)=\underline{v}+\left(\frac{n-1}{n}\right)\left(v_{i}-\underline{v}\right)$.

Since the highest-value bidder will determine the price, the seller's expected revenue will be $E\{\underline{v}+$ $\left.\left(\frac{n-1}{n}\right)\left(\max _{i=1, \ldots, n} v_{i}-\underline{v}\right)\right\}$, so using our result that $E\left\{\max _{i=1, \ldots, n} v_{i}\right\}=\underline{v}+\left(\frac{n}{n+1}\right)(\bar{v}-\underline{v})$ yields that the 
Note that the proportion of buyers with valuations above any price $v$ is linear in $v$, that is, $q(v) \equiv 1-F(v)=\frac{\bar{v}-v}{\bar{v}-\underline{v}}$. Therefore $v=\bar{v}-(\bar{v}-\underline{v}) q$, so the uniform distribution corresponds to linear demand (since $v$ plays the role of price). It follows that the marginal revenue curve is just linear and twice as steep as the demand curve, that is, $M R(q(v))=\bar{v}-2(\bar{v}-\underline{v}) q$, which implies $M R(v)=\bar{v}-2(\bar{v}-\underline{v})\left(\frac{\bar{v}-v}{\bar{v}-\underline{v}}\right)=2 v-\bar{v}{ }^{138}$

Since $E\left\{\max _{i=1, \ldots, n} v_{i}\right\}=\underline{v}+\left(\frac{n}{n+1}\right)(\bar{v}-\underline{v})$, the expected marginal revenue of the highest bidder equals $\underline{v}+\left(\frac{n-1}{n+1}\right)(\bar{v}-\underline{v})$, which confirms our earlier result that this is the expected revenue from any standard auction (without a reserve price).

Furthermore, since the marginal revenue curve is downward sloping, an optimal (that is, expected-revenue maximising) auction is any standard auction together with a reserve price, $p_{r}=\frac{\bar{v}}{2}$ (so that $M R\left(p_{r}\right)=0$ ), below which no sale will be made.

\section{Bidding with Common Values, and the Winner's Curse}

Now let the bidders have signals $t_{i}$, and $v_{i}=\alpha t_{i}+\beta \sum_{j \neq i} t_{j}$. (So $\beta=0$ is the private values case, and $\alpha=\beta$ is pure common values; we assume $\alpha \geq \beta$.) Let $t_{(j)}$ be the actual $j^{\text {th }}$ highest signal.

In the symmetric equilibrium of an ascending auction each player quits where she would just be indifferent about finding herself a winner. So the first quit is at price $(\alpha+(n-1) \beta) t_{(n)}$, since that would be the actual value to all if all bidders had this signal; the remaining bidders all observe this and the next quit is at $\beta t_{(n)}+(\alpha+(n-2) \beta) t_{(n-1)}$ since this would be the current quitter's value if all the other remaining bidders were to quit with her; the other bidders all observe this and infer the next lowest signal, etc. The final quit, and so actual sale price is at $\widehat{p}=\beta \sum_{j=3}^{n} t_{(j)}+(\alpha+\beta) t_{(2)}$.

To check this is the equilibrium, note, for example, that if the player with the second-highest signal, $t_{(2)}$, waited to quit and found herself a winner at a price $\widehat{p}+$ $(\alpha+\beta) \varepsilon$ she would then infer $t_{(1)}=t_{(2)}+\varepsilon$ (since the final opponent is bidding symmetrically to her) hence that the value of the object to her was just $\widehat{p}+\beta \varepsilon$, so she had lost money. But when the price reached $\widehat{p}-(\alpha+\beta) \varepsilon$, she could infer $t_{(1)} \geq t_{(2)}-\varepsilon$ hence that the value of the object to her was at least $\widehat{p}-\beta \varepsilon$, so quitting early would expected revenue is $\underline{v}+\left(\frac{n-1}{n+1}\right)(\bar{v}-\underline{v})$, confirming revenue equivalence with the second-price auction forms.

${ }^{138}$ Obviously, we can obtain this equation by using the definition, $M R(v)=v-\frac{1-F(v)}{f(v)}$, in Appendix B. 
have given up the opportunity of making some money (in the states in which the final opponent would have quit close to this price). ${ }^{139}$

Note that when the player with the second-highest signal quits, she knows (assuming equilibrium behaviour) that the remaining signal is (weakly) higher than hers. So she is sure the actual value of the object to her cannot be less than the price at which she is quitting, and that the expected value is higher. This illustrates the winner's curse. The point is that what is relevant to her is not the expected value of the

${ }^{139}$ The principle for solving the case where bidders' value functions are asymmetric is similar, and clarifies the argument. Assume just two bidders, for simplicity, with signal $t_{i}, t_{j}$ and values $v_{i}\left(t_{i}, t_{j}\right)$ and $v_{j}\left(t_{i}, t_{j}\right)$. Assume that in equilibrium $t_{i}$ quits at the same time as an opponent of type $t_{j}=w_{i}\left(t_{i}\right)$, in which $w_{i}(\cdot)$ is a strictly increasing function. So

$$
b_{i}\left(t_{i}\right)=b_{j}\left(w_{i}\left(t_{i}\right)\right)
$$

and $t_{i}$ will beat all opponents with types $t_{j}<w_{i}\left(t_{i}\right)$, and lose to all higher types.

Now if $t_{i}$ deviated from her equilibrium strategy and waited a tiny bit longer to quit, she would win against all $t_{j} \leq w_{i}\left(t_{i}\right)$ at the same prices as before, and she would also win against a few additional types of $j$ with signals of (slightly above) $w_{i}\left(t_{i}\right)$, at a price of (slightly above) $b_{i}\left(t_{i}\right)$. Her value of winning in these additional cases would be (slightly above) $v_{i}\left(t_{i}, w_{i}\left(t_{i}\right)\right)$, so if $b_{i}\left(t_{i}\right)$ were (strictly) less than $v_{i}\left(t_{i}, w_{i}\left(t_{i}\right)\right)$, then deviating to win against a few additional types would be profitable. So $b_{i}\left(t_{i}\right) \geq v_{i}\left(t_{i}, w_{i}\left(t_{i}\right)\right)$.

Similarly, if $t_{i}$ were to quit a tiny bit earlier than her equilibrium quitting price, it would make no difference except that she would lose against a few types with signals (slightly below) $w_{i}\left(t_{i}\right)$ at prices of (slightly below) $b_{i}\left(t_{i}\right)$, and type $t_{i}$ would wish to do this unless $b_{i}\left(t_{i}\right) \leq v_{i}\left(t_{i}, w_{i}\left(t_{i}\right)\right)$.

So

$$
b_{i}\left(t_{i}\right)=v_{i}\left(t_{i}, w_{i}\left(t_{i}\right)\right)
$$

That is, $t_{i}$ bids up to the value at which she would make no money if she were to find herself the winner.

Similarly

$$
b_{j}\left(t_{j}\right)=v_{j}\left(w_{j}\left(t_{j}\right), t_{j}\right)
$$

Substituting the value $t_{j}=w_{i}\left(t_{i}\right)$ into this equation yields

$$
b_{j}\left(w_{i}\left(t_{i}\right)\right)=v_{j}\left(w_{j}\left(w_{i}\left(t_{i}\right)\right), w_{i}\left(t_{i}\right)\right) .
$$

But $b_{j}\left(w_{i}\left(t_{i}\right)\right)=b_{i}\left(t_{i}\right)$ by $(*)$. And by definition $w_{j}\left(w_{i}\left(t_{i}\right)\right)=t_{i}$. (That is, if $t_{i}$ quits at the same time as $w_{i}\left(t_{i}\right)$, then the type that quits at the same time as $w_{i}\left(t_{i}\right)$ - this type is $w_{j}\left(w_{i}\left(t_{i}\right)\right)$ - is $\left.t_{i}.\right)$ So

$$
b_{i}\left(t_{i}\right)=v_{j}\left(t_{i}, w_{i}\left(t_{i}\right)\right)
$$

Comparing with $(* *)$ we have

$$
v_{i}\left(t_{i}, w_{i}\left(t_{i}\right)\right)=v_{j}\left(t_{i}, w_{i}\left(t_{i}\right)\right)
$$

That is, players have the same values when they have types that quit at the same time.

So to find the bidding strategies we solve this last equation for the function $w_{i}\left(t_{i}\right)$, and then substitute this function back into $(* *)$ to yield $i$ 's bidding function. (Note that this procedure does not necessarily yield an equilibrium, although it does so in natural two-bidder or symmetric examples. See Maskin (1992).) 
object, but rather its expected value conditional on her winning it. ${ }^{140}$ Only when she wins the object does she care about its value, so she quits exactly at its value conditional on her winning. Exactly the same effect-that winning the auction is bad news about opponents' signals, so bids must be adjusted down to allow for the "winner's curse" - arises in the other auction types.

Note that the ascending auction equilibrium does not depend on the bidders' signals being independent or on their distributions (which can be different for different bidders), or on the bidders being risk-neutral. However, these properties do not extend to the other standard auctions. So henceforth assume the signals are independent and uniform on $[0, \bar{t}]$, and the bidders are risk-neutral.

In a second-price sealed-bid auction the logic is similar to that for the ascending auction. Bidder $i$ with signal $t_{i}$ is willing to pay anything up to her expected value conditional on her winning the object but being just tied with one other with the same signal. The difference is that the bidder does not see the other $(n-2)$ opponents' bids, so estimates their signals at $\frac{t_{i}}{2}$ (since conditional on them being below $t_{i}$, they are uniformly distributed below $\left.t_{i}\right)$. So $i$ bids $\beta(n-2) \frac{t_{i}}{2}+(\alpha+\beta) t_{i}=\left(\alpha+\frac{n}{2} \beta\right) t_{i}{ }^{141}$

The simplest way to solve for first-price bidding strategies is to use revenue equivalence. $^{142}$ Conditional on winning the second-price auction, a bidder with signal $t_{i}$ expects to pay $\left(\alpha+\frac{n}{2} \beta\right) \widehat{t}$ in which $\widehat{t}$ is the expected highest of $n-1$ signals uniformly distributed on $\left[0, t_{i}\right]$, that is, $\widehat{t}=\left(\frac{n-1}{n}\right) t_{i}$. So $i$ bids this expected payment, that is, $\left(\frac{n-1}{n}\right)\left(\alpha+\frac{n}{2} \beta\right) t_{i}$.

\section{Bidding with Affiliated Signals, and Revenue Rankings}

A tractable example of affiliated information that illustrates the revenue-ranking results derived in Appendix C (and is also useful for developing other examples ${ }^{143}$ ) has risk-neutral bidders $i=1, \ldots, n$ each of whom receives a signal $t_{i}$ that is independently drawn from a uniform distribution on $\left[v-\frac{1}{2}, v+\frac{1}{2}\right]$ where $v$ is the (pure) common value of a single object for sale. Assume a "diffuse prior" for $v$, that is, all values of $v$ are equally likely. (More formally we can let $v$ be uniformly distributed on $[-M,+M]$

\footnotetext{
${ }^{140}$ This statement assumes risk-neutrality, but the point we are making obviously does not.

${ }^{141}$ We can also confirm this is the equilibrium either by revenue equivalence with the ascending auction, or by a similar argument to that for the ascending auction - the only first-order effect of $i$ bidding a small amount $(\alpha+\beta) \varepsilon$ more is if $i$ moves from coming second to winning, etc.

${ }^{142} \mathrm{An}$ alternative is the direct method, see note 120 .

${ }^{143}$ Most examples of affiliated information are very hard to work with.
} 
and take the limit as $M \rightarrow \infty$.) So a higher value of $t_{i}$ makes a higher value of $v$ more likely, and hence higher values of the other signals more likely, and it can be checked that this example satisfies the formal definition of affiliation.

Let the $j^{\text {th }}$ highest actual signal be $t_{(j)}$, and observe that conditional on all the signals $t_{1}, \ldots, t_{n}$, the expected value of $v$ equals $\frac{1}{2}\left(t_{(1)}+t_{(n)}\right)$ (since any value of $v \in$ $\left[t_{(1)}-\frac{1}{2}, t_{(n)}+\frac{1}{2}\right]$ is equally probable).

We now compute the symmetric equilibria of the standard auction types.

In an ascending auction, the first quit will be at price $t_{(n)}$ (since that is where the lowest-signal bidder would be indifferent about winning were everyone else to quit simultaneously with her), and every other bidder $i$ will then infer $t_{(n)}$ and quit at $\frac{1}{2}\left(t_{(n)}+\right.$ $t_{i}$ ) (since that is where each $i$ would be just indifferent about finding herself the winner). The price paid by the winner will therefore be $\frac{1}{2}\left(t_{(n)}+t_{(2)}\right)$ which, using our result about the uniform distribution, on average equals $\frac{1}{2}\left(\left[v-\frac{1}{2}+\left(\frac{1}{n+1}\right)\right]+\left[v-\frac{1}{2}+\left(\frac{n-1}{n+1}\right)\right]\right)=$ $v-\frac{1}{2}\left(\frac{1}{n+1}\right)$.

In a sealed-bid second-price auction, each bidder $i$ bids her expected value, conditional on being tied for winner with one other bidder (see previous subsection). That is, $i$ bids thinking of herself as being the highest of $n-1$ bidders uniformly drawn from $\left[v-\frac{1}{2}, v+\frac{1}{2}\right]$ and tied with one other, so on average, in this case, $t_{i}=\left[v-\frac{1}{2}+\left(\frac{n-1}{n}\right)\right]$ so $i$ 's estimate of $v$ in this case, and hence her bid, equals $t_{i}+\frac{1}{2}-\left(\frac{n-1}{n}\right)$. On average, the second-highest bidder of $n$ bidders actually has signal $t_{(2)}=\left[v-\frac{1}{2}+\left(\frac{n-1}{n+1}\right)\right]$ so bids $\left[v-\frac{1}{2}+\left(\frac{n-1}{n+1}\right)\right]+\left[\frac{1}{2}-\left(\frac{n-1}{n}\right)\right]$. So the expected revenue from this auction equals $v-\left(\frac{n-1}{n}\right)\left(\frac{1}{n+1}\right)$.

In a first-price auction, likewise, each bidder $i$ bids $t_{i}-x$ for some $x$; this is because of our "diffuse prior" assumption which means that $i$ 's signal gives her no information about whether she is high or low relative to others' signals or the "truth", and so should not affect how close she bids to her signal. Let $t_{i}=v-\frac{1}{2}+T_{i}$. In equilibrium $i$ will have the highest signal, and so win the auction, with probability $T_{i}^{n-1}$, and will earn $v-\left(t_{i}-x\right)=x+\frac{1}{2}-T_{i}$ when she wins. So if, instead, $i$ had deviated from the symmetric equilibrium by bidding a small amount $\varepsilon$ more, as if she had signal $t_{i}+\varepsilon$, she would win $x+\frac{1}{2}-T_{i}(-\varepsilon)$ with additional probability $\left(T_{i}+\varepsilon\right)^{n-1}-\left(T_{i}\right)^{n-1} \approx(n-1) \varepsilon T_{i}^{n-2}$, for small $\varepsilon$, but pay an additional $\varepsilon$ in the $T_{i}^{n-1}$ cases in which she would have won anyway. In equilibrium $i$ must be just indifferent about the small deviation so, since 
she knows only that $T_{i}$ is uniformly distributed on $[0,1]$,

$$
\int_{T_{i}=0}^{1}\left[(n-1) \varepsilon T_{i}^{n-2}\left(x+\frac{1}{2}-T_{i}\right)-\varepsilon T_{i}^{n-1}\right] d T_{i}=0
$$

(we are omitting terms in $\varepsilon^{2}$ and higher orders of $\varepsilon$ )

$$
\Rightarrow\left[\varepsilon T_{i}^{n-1}\left(x+\frac{1}{2}\right)-(n-1) \varepsilon \frac{T_{i}^{n}}{n}-\varepsilon \frac{T_{i}^{n}}{n}\right]_{T_{i}=0}^{1}=0 \quad \Rightarrow x=\frac{1}{2} .
$$

So $i$ bids $t_{i}-\frac{1}{2}$, and the price is set by the bidder with the highest signal, $t_{(1)}$, which equals $v-\frac{1}{2}+\left(\frac{n}{n+1}\right)$ on average. So the expected revenue from the auction is $v-\left(\frac{1}{n+1}\right)$.

Those results confirm the Milgrom and Weber revenue rankings of the standard auctions. $^{144}$

\footnotetext{
${ }^{144}$ Of course, since signals are affiliated an optimal auction can extract all the surplus for the auctioneer (see Section 6). Here it suffices to ask each bidder to declare $t_{i}$, allocate the good to the high bidder (say) at the "fair" price $\frac{1}{2}\left[t_{(1)}+t_{(n)}\right]$, and ensure truth-telling behavior by imposing large fines on all the bidders if $t_{(1)}-t_{(n)}>1$.
} 


\section{Appendix E: Bibliography}

Sections 2-14 of this bibliography correspond to those sections of this paper. Articles marked $\left(^{*}\right)$ are reproduced in The Economic Theory of Auctions (see Section 18).

\section{Survey and Guide to the Literature}

* Klemperer, P. D. (1999) Auction Theory: A Guide to the Literature. Journal of Economic Surveys, 13.

\section{Early Literature}

* Vickrey, W. (1961) Counterspeculation, Auctions, and Competitive Sealed Tenders. Journal of Finance, 16, 8-37.

* Vickrey, W. (1962) Auction and Bidding Games. In Recent Advances in Game Theory (pp. 15-27). Princeton, New Jersey: The Princeton University Conference.

* Griesmer, J. H., Levitan, R. E., and Shubik, M. (1967) Toward a Study of Bidding Processes Part IV: Games with Unknown Costs. Naval Research Logistics Quarterly, 14, 415-33.

* Ortega-Reichert, A. (1968) A Sequential Game with Information Flow. Chapter 8 in Models for Competitive Bidding Under Uncertainty, Stanford University PhD thesis (and Technical Report No. 8, Department of Operations Research, Stanford University) (pp. 232-54).

* Wilson, R. (1969) Competitive Bidding with Disparate Information. Management Science, 15, 446-48.

Friedman, L. (1956) A Competitive Bidding Strategy. Operations Research, 4, 104-12.

Wilson, R. (1967) Competitive Bidding with Asymmetric Information. Management Science, 13, A816-20.

Rothkopf, M. H. (1969) A Model of Rational Competitive Bidding. Management Science, 15, 362-73. (See also Rothkopf, M. H. (1980) On Multiplicative Bidding Strategies. Operations Research, 25, 570-75.)

Capen, E. C., Clapp, R. V., and Campbell, W. M. (1971) Competitive Bidding in High-Risk Situations. Journal of Petroleum Technology, 23, 641-53.

Vickrey, W. (1976) Auctions Markets and Optimum Allocations. In Y. Amihud (ed.), Bidding and Auctioning for Procurement and Allocation (pp. 13-20). Studies in Game Theory and Mathematical Economics. New York: New York University Press. 


\section{Introduction to the Recent Literature}

* McAfee, R. P. and McMillan, J. (1987a) Auctions and Bidding. Journal of Economic Literature, 25, 699-738.

* Maskin, E. S. and Riley, J. G. (1985) Auction Theory with Private Values. American Economic Review, 75, 150-55.

Riley, J. G. (1989) Expected Revenue from Open and Sealed Bid Auctions. Journal of Economic Perspectives, 3, 41-50.

\section{The Basic Analysis of Optimal Auctions, and Revenue Equivalence}

* Myerson, R. B. (1981) Optimal Auction Design. Mathematics of Operations Research, $6,58-73$.

* Riley, J. G. and Samuelson, W. F. (1981) Optimal Auctions. American Economic Review, 71, 381-92.

* Bulow, J. I. and Roberts, D. J. (1989) The Simple Economics of Optimal Auctions. Journal of Political Economy, 97, 1060-90.

* Vickrey 1961, 1962 (see under 2).

* Bulow and Klemperer 1996 (see under 8.2).

Harris, M. and Raviv, A. (1981) Allocation Mechanisms and the Design of Auctions. Econometrica, 49, 1477-99.

\section{Risk Aversion}

* Maskin, E. S. and Riley, J. G. (1984) Optimal Auctions with Risk Averse Buyers. Econometrica, 52, 1473-1518.

* Matthews, S. A. (1987) Comparing Auctions for Risk-Averse Buyers: A Buyer's Point of View. Econometrica, 55, 633-46.

Matthews, S. A. (1983) Selling to Risk Averse Buyers with Unobservable Tastes. Journal of Economic Theory, 3, 370-400.

Waehrer, K., Harstad, R. M. and Rothkopf, M. H. (1998) Auction Form Preferences of Risk-Averse Bidtakers. Rand Journal of Economics, 29, 179-192. 


\section{Correlation and Affiliation}

* Milgrom, P. R. and Weber, R. J. (1982a) A Theory of Auctions and Competitive Bidding. Econometrica, 50, 1089-1122.

* Cremer, J. and McLean, R. P. (1985) Optimal Selling Strategies under Uncertainty for a Discriminatory Monopolist when Demands Are Interdependent. Econometrica, $53,345-61$.

* Levin, D. and Smith, J. L. (1996a) Optimal Reservation Prices in Auctions. Economic Journal, 106, 1271-83.

Cremer, J. and McLean, R. P. (1988) Full Extraction of the Surplus in Bayesian and Dominant Strategy Auctions. Econometrica, 56, 1247-57.

McAfee, R. P., McMillan, J., and Reny, P. J. (1989) Extracting the Surplus in the Common Value Auction. Econometrica, 57, 1451-60.

McAfee, R. P. and Reny, P. J. (1992) Correlated Information and Mechanism Design. Econometrica, 60, 395-421.

Perry, M. and Reny, P. J. (forthcoming) On the Failure of the Linkage Principle in Multi-Unit Auctions. Econometrica.

\section{Asymmetries}

\subsection{Private Value Differences}

* McAfee, R. P. and McMillan, J. (1989) Government Procurement and International Trade. Journal of International Economics, 26, 291-308.

* Maskin, E. S. and Riley, J. G. (1999) Asymmetric Auctions. Review of Economic Studies, forthcoming.

* Maskin and Riley, 1985 (see under 3).

* Griesmer et al, 1967 (see under 2.).

Marshall, R. C., Meurer, M. J., Richard, J-F., and Stromquist, W. (1994) Numerical Analysis of Asymmetric First Price Auctions. Games and Economic Behaviour, 7, 193-220.

Rothkopf, M. H., Harstad, R. M., and Fu, Y. (1997) Is Subsidizing Inefficient Bidders Actually Costly? Mimeo, Rutgers University.

7.2 Almost Common Values 
* Bikhchandani, S. (1988) Reputation in Repeated Second-Price Auctions. Journal of Economic Theory, 46, 97-119.

* Klemperer, P. D. (1998) Auctions with Almost Common Values. European Economic Review, 42, 757-69.

Bulow, J. I., Huang, M., and Klemperer, P. D. (1999) Toeholds and Takeovers. Journal of Political Economy, 107, forthcoming.

7.3 Information Advantages

* Milgrom, P. R. and Weber, R. J. (1982b) The Value of Information in a Sealed-Bid Auction. Journal of Mathematical Economics, 10, 105-14.

* Milgrom, 1981 (see under 8.3).

Engelbrecht-Wiggans, R., Milgrom, P. R., and Weber, R. J. (1983) Competitive Bidding and Proprietary Information. Journal of Mathematical Economics, 11, 161-69.

\section{Entry Costs and the Number of Bidders}

\subsection{Endogenous Entry of Bidders}

* Levin, D. and Smith, J. L. (1994) Equilibrium in Auctions with Entry. American Economic Review, 84, 585-99.

* Engelbrecht-Wiggans, R. (1993) Optimal Auctions Revisited. Games and Economic Behaviour, 5, 227-39.

* Matthews, S. A.(1984) Information Acquisition in Discriminatory Auctions. In M. Boyer and R. E. Kihlstrom (eds.), Bayesian Models in Economic Theory (pp. 181207). New York: North Holland.

* Fishman, M. J. (1988) A Theory of Pre-emptive Takeover Bidding. Rand Journal of Economics, 19, 88-101.

Engelbrecht-Wiggans, R. (1987) Optimal Reservation Prices in Auctions. Management Science, 33, 763-70.

McAfee, R. P. and McMillan, J. (1987c) Auctions with Entry. Economics Letters, 23, $343-47$.

McAfee, R. P. and McMillan, J. (1988) Search Mechanisms. Journal of Economic Theory, 44, 99-123.

Harstad, R. M. (1990) Alternative Common Values Auction Procedures: Revenue Comparisons with Free Entry. Journal of Political Economy, 98, 421-29. 
Menezes, F. M. and Monteiro, P. K. (1997) Auctions with Endogenous Participation. Mimeo, Australian National University and IMPA.

Persico, N. (1997) Information Acquisition in Auctions. Working Paper, U.C.L.A.

Gilbert, R. and Klemperer, P. D. (1999) An Equilibrium Theory of Rationing. Rand Journal of Economics, 30, forthcoming.

\subsection{The Value of Additional Bidders}

* Bulow, J. I. and Klemperer, P. D. (1996) Auctions vs. Negotiations. American Economic Review, 86, 180-94.

\subsection{Information Aggregation with Large Numbers of Bidders}

* Wilson, R. (1977) A Bidding Model of Perfect Competition. Review of Economic Studies, 44, 511-18.

* Milgrom, P. R. (1981) Rational Expectations, Information Acquisition, and Competitive Bidding. Econometrica, 49, 921-43.

Milgrom, P. R. (1979) A Convergence Theorem for Competitive Bidding with Differential Information. Econometrica, 47, 679-88.

Pesendorfer, W. and Swinkels, J. M. (1997) The Loser's Curse and Information Aggregation in Common Value Auctions. Econometrica, 65, 1247-81.

\subsection{Unknown Number of Bidders}

* Matthews, 1987 (see under 5).

McAfee, R. P. and McMillan, J. (1987b) Auctions with a Stochastic Number of Bidders. Journal of Economic Theory, 43, 1-19.

Harstad, R.M., Kagel, J., and Levin, D. (1990) Equilibrium Bid Functions for Auctions with an Uncertain Number of Bidders. Economic Letters, 33, 35-40.

Levin, D. and Smith, J. L. (1996b) Ranking Auctions with Risk Averse Bidders. Journal of Economic Theory, 68, 549-61.

Piccione, M. and Tan, G. (1996) A Simple Model of Expert and Non Expert Bidding in First Price Auctions. Journal of Economic Theory, 70, 501-15.

\section{Collusion}

* Robinson, M. S. (1985) Collusion and the Choice of Auction. Rand Journal of Eco- 
nomics, 16, 141-45.

* McAfee, R. P and McMillan, J. (1992) Bidding Rings. American Economic Review, $82,579-99$.

* Hendricks, K. and Porter, R. H. (1989) Collusion in Auctions. Annales D' Economie et de Statistique, 15/16, 217-30.

Graham, D. A. and Marshall, R. C. (1987) Collusive Bidder Behavior at Single-Object Second-Price and English Auctions. Journal of Political Economy, 95, 1217-39.

Graham, D. A., Marshall, R. C., and Richard, J-F. (1990) Differential Payments within a Bidder Coalition and the Shapley Value. American Economic Review, 80, 493-510.

Mailath, G. J. and Zemsky, P. (1991) Collusion in Second Price Auctions with Heterogeneous Bidders. Games and Economic Behavior, 3, 467-86.

Hendricks, K., Porter, R. H., and Tan, G. (1999) Joint Bidding in Federal Offshore Oil and Gas Lease Auctions. Working Paper, University of British Columbia.

\section{Multiple Units}

\subsection{Optimal Auctions}

* Maskin, E. S. and Riley, J. G. (1989) Optimal Multi-Unit Auctions. In Frank Hahn (ed.), The Economics of Missing Markets, Information, and Games (pp. 312-335). Oxford: Oxford University Press, Clarendon Press.

* Palfrey, T. R. (1983) Bundling Decisions by a Multiproduct Monopolist with Incomplete Information. Econometrica, 51, 463-84.

Avery, C. and Hendershott, T. (1997) Bundling and Optimal Auctions of Multiple Goods. Mimeo, School of Government, Harvard University and Graduate School of Business, Stanford University.

Armstrong, M. (1998) Optimal Multi-Object Auctions. Mimeo, Oxford University.

Rothkopf, M. H., Pekeč, A., and Harstad, R. M. (1998) Computationally Manageable Auctions. Working Paper, Faculty of Management and Rutgers Center for Operations Research, Rutgers University.

\subsection{Simultaneous Auctions}

* Wilson, R. (1979) Auctions of Shares. Quarterly Journal of Economics, 93, 675-89.

* Back, K. and Zender, J. F. (1993) Auctions of Divisible Goods. Review of Financial Studies, 6, 733-64. 
* Anton, J. J. and Yao, D. A. (1992) Coordination in Split Award Auctions. Quarterly Journal of Economics, 107, 681-701.

* Klemperer, P. D. and Meyer, M. A. (1989) Supply Function Equilibria in Oligopoly Under Uncertainty. Econometrica, 57, 1243-77.

* Hansen, R. G. (1988) Auctions with Endogenous Quantity. Rand Journal of Economics, 19, 44-58.

Maxwell, C. (1983) Auctioning Divisible Commodities: A Study of Price Determination. Dissertation, Harvard University.

Bernheim, B. D. and Whinston, M. D. (1986) Menu Auctions, Resource Allocation, and Economic Influence. Quarterly Journal of Economics, 101, 1-32.

Anton, J. J. and Yao, D. A. (1989) Split Awards, Procurement, and Innovation. Rand Journal of Economics, 20, 538-52.

Daripa, A. (1996a) Quantities Rather Than Prices: Market Allocation, Informational Free-Rides and the Value of Inside Information. Mimeo, Birkbeck College, London.

Daripa, A. (1996b) A Theory of Treasury Auctions. Mimeo, Birkbeck College, London.

Nyborg, K. G. (1997) On Complicity in Share Auctions. Mimeo, London Business School.

Engelbrecht-Wiggans, R. and Kahn, C. M. (1998) Multi-unit Auctions with Uniform Prices. Economic Theory, 12, 227-58.

Engelbrecht-Wiggans, R. and Kahn, C. M. (1998) Multi-Unit Pay-Your-Bid Auctions with Variable Awards. Games and Economic Behavior, 23, 25-42.

Wang, J. J. D. and Zender, J. F. (1998) Auctioning Divisible Goods. Working Paper, Duke University and University of Utah.

10.3 Sequential Auctions

(i) Bidders demand only a single unit each

* Milgrom, P. R. and Weber, R. J. (1982c) A Theory of Auctions and Competitive Bidding II. Mimeo, Stanford University and Northwestern University.

* Bulow, J. I. and Klemperer, P. D. (1994) Rational Frenzies and Crashes. Journal of Political Economy, 102, 1-23.

* McAfee, R. P. and Vincent, D. (1993) The Declining Price Anomaly. Journal of Economic Theory, 60, 191-212. 
Bernhardt, D. and Scoones, D. (1994) A Note on Sequential Auctions. American Economic Review, 84, 653-57.

Engelbrecht-Wiggans, R. (1994) Sequential Auctions of Stochastically Equivalent Objects. Economics Letters, 44, 87-90.

von der Fehr, N-H. M. (1994) Predatory Bidding in Sequential Auctions. Oxford Economic Papers, 46, 345-56.

Gale, I. L. and Hausch, D. B. (1994) Bottom-Fishing and Declining Prices in Sequential Auctions. Games and Economic Behavior, 7, 318-31.

Robert, J., Laffont, J-J., and Loisel, P. (1994) Repeated Descending-Price Auctions I: Theory. Mimeo, Université de Montreal, Université de Toulouse, and INRA.

Beggs, A. W. and Graddy, K. (1997) Declining Values and the Afternoon Effect: Evidence from Art Auctions. Rand Journal of Economics, 28, 544-65.

McAfee, R. P. and Vincent, D. (1997) Sequentially Optimal Auctions. Games and Economic Behaviour, 18, 246-76.

(ii) Bidders with multi-unit demand

* Weber, R. J. (1983) Multi-Object Auctions. In Richard Engelbrecht-Wiggans, Martin Shubik, and Robert M. Stark (eds), Auctions, Bidding, and Contracting (pp. 165-91). New York: New York University Press.

* Ortega-Reichert, 1968 (see under 2).

Hausch, D. B. (1986) Multi-Object Auctions: Sequential vs. Simultaneous Sales. Management Science, 32, 1599-1610.

Pitchik, C. and Schotter, A. (1988) Perfect Equilibria in Budget Constrained Sequential Auctions: An Experimental Study. Rand Journal of Economics, 19, 363-88.

Black, J. and de Meza, D. (1992) Systematic Price Divergences Between Successive Auctions Are No Anomaly. Journal of Economics and Management Strategy, 1, 607-28.

Krishna, K. (1993) Auctions with Endogenous Valuations: The Persistence of Monopoly Revisited. American Economic Review, 83, 147-60.

Robert, J. (undated, $\approx 1995$ ) Sequential Descending-Price Auctions with Multi-Unit Demand. Mimeo, Université de Montreal.

Gale, I. L. and Stegeman, M. (1995) Sequential Auctions of Endogenously Valued Objects. Mimeo, Georgetown University and Virginia Polytechnic Institute. 
Pitchik, C. (1995) Budget-Constrained Sequential Auctions with Incomplete Information. Mimeo, University of Toronto.

Gale, I. L., Hausch, D. B., and Stegeman, M. (1998) Sequential Procurement Auctions with Subcontracting. Mimeo, Georgetown University, University of Wisconsin and Virginia Polytechnic Institute.

von der Fehr, N-H. M. and Riis, C. (1999) Option Values in Sequential Markets. Mimeo, University of Oslo and Norweigian School of Management.

\subsection{Efficient Auctions}

Ausubel, L. (1998) An Efficient Ascending-Bid Auction for Multiple Objects. Working Papers, University of Maryland.

Ausubel, L. and Cramton, P. (1998) Demand Reduction and Inefficiency in Multi-Unit Auctions. Mimeo, University of Maryland.

Dasgupta, P. S. and Maskin, D. (1998) Efficient Auctions. Working Paper, Cambridge University and Harvard University.

Jehiel, P. and Moldovanu, B. (1998) Efficient Design with Interdependent Valuations. Working Paper, University College London and University of Mannheim.

Perry, M. and Reny, P. J. (1998) Ex-Post Efficient Auctions for Agents with Interdependent Values. Working Paper, Hebrew University of Jerusalem and University of Pittsburgh.

Bikhchandani, S. (1999) Auctions of Heterogeneous Objects. Games and Economic Behaviour.

\section{Royalties, Incentive Contracts, and Payments for Quality}

* Riley, J. G. (1988), Ex Post Information in Auctions. Review of Economic Studies, 55, 409-30.

* Laffont, J-J. and Tirole, J. (1987) Auctioning Incentive Contracts. Journal of Political Economy, 95, 921-37.

* Che, Y-K. (1993) Design Competition through Multidimensional Auctions. Rand Journal of Economics, 24, 668-80.

McAfee, R. P. and McMillan, J. (1986) Bidding for Contracts: A Principal-Agent Analysis. Rand Journal of Economics, 17, 326-38.

McAfee, R. P. and McMillan, J. (1987d) Competition for Agency Contracts. Rand Journal of Economics, 18, 296-307. 
Riordan, M. H. and Sappington, D. E. M. (1987) Awarding Monopoly Franchises. American Economic Review, 77, 375-87.

Branco, F. (1997) The Design of Multidimensional Auctions. Rand Journal of Economics, 28, 63-81.

\section{Double Auctions, etc}

\subsection{Double Auctions}

* Chatterjee, K. and Samuelson, W. (1983) Bargaining under Incomplete Information. Operations Research, 31, 835-51.

* Wilson, R. (1985) Incentive Efficiency of Double Auctions. Econometrica, 53, 1101-15.

* Rustichini, A., Satterthwaite, M. A., and Williams, S. R. (1994) Convergence to Efficiency in a Simple Market with Incomplete Information. Econometrica, 62, 1041-63.

* McAfee, R. P. (1992) A Dominant Strategy Double Auction. Journal of Economic Theory, 56, 434-50.

Leininger, W., Linhart, P. B., and Radner, R. (1989) Equilibria of the Sealed Bid Mechanism for Bargaining with Incomplete Information. Journal of Economic Theory, 48, 63-106.

Satterthwaite, M. A. and Williams, S. R. (1989a) The Rate of Convergence to Efficiency in the Buyer's Bid Double Auction as the Market Becomes Large. Review of Economic Studies, 56, 477-98.

Satterthwaite, M. A. and Williams, S. R. (1989b) Bilateral Trade with the Sealed Bid k-Double Auction: Existence and Efficiency. Journal of Economic Theory, 48, 107-33.

\subsection{Related Two-Sided Trading Mechanisms}

* Myerson, R. B. and Satterthwaite, M. A. (1983) Efficient Mechanisms for Bilaterial Trade. Journal of Economic Theory, 29, 265-81.

* Cramton, P., Gibbons, R., and Klemperer, P. D. (1987) Dissolving a Partnership Efficiently. Econometrica, 55, 615-32.

\section{Other Topics}

\subsection{Budget Constraints}

* Che, Y-K. and Gale, I. L. (1998) Standard Auctions with Financially Constrained 
Bidders. Review of Economic Studies, 65, 1-21.

Pitchik and Schotter, 1988 (see under 10.3(ii)).

Pitchik, 1995 (see under 10.3(ii)).

Che, Y-K. and Gale, I. L. (1996) Expected Revenue of All-Pay Auctions and FirstPrice Sealed-Bid Auctions with Budget Constraints. Economics Letters, 50, 367-71.

Benoît, J-P. and Krishna, V. (1998) Multi-Object Auctions with Budget Constrained Bidders. Working Paper, New York University and Pennsylvania State University.

\subsection{Externalities between Bidders}

* Jehiel, P. and Moldovanu, B. (1996) Strategic Nonparticipation. Rand Journal of Economics, 27, 84-98.

Jehiel, P., Moldovanu, B., and Stacchetti, E. (1996) How (Not) to Sell Nuclear Weapons. American Economic Review, 86, 814-29.

Caillaud, B. and Jehiel, P. (1998) Collusion in Auctions with Externalities. Rand Journal of Economics, 29, 680-702.

\subsection{Jump Bidding}

* Avery, C. (1998) Strategic Jump Bidding in English Auctions. Review of Economic Studies, 65, 185-210.

* Fishman, 1988 (see under 8.1).

Daniel, K. and Hirshleifer, D. (1995) A Theory of Costly Sequential Bidding. Mimeo, Universities of Chicago and Michigan.

\subsection{War of Attrition}

* Bulow, J. I. and Klemperer, P. D. (1999a) The Generalized War of Attrition. American Economic Review, 89, forthcoming.

Riley, J. G. (1980) Strong Evolutionary Equilibrium and The War of Attrition. Journal of Theoretical Biology, 82, 383-400.

Bliss, C. and Nalebuff, B. (1984) Dragon-Slaying and Ballroom Dancing: The Private Supply of a Public Good. Journal of Public Economics, 25, 1-12.

Fudenberg, D. and Tirole, J. (1986) A Theory of Exit in Duopoly. Econometrica, 54, 943-60.

Krishna, V. and Morgan, J. (1997) An Analysis of the War of Attrition and the All- 
Pay Auction. Journal of Economic Theory, 72, 343-62.

13.5 Competing Auctioneers

* McAfee, R. P. (1993) Mechanism Design by Competing Sellers. Econometrica, 61, 1281-1312.

Peters, M. and Severinov, S. (1997) Competition Among Sellers Who Offer Auctions Instead of Prices. Journal of Economic Theory, 75, 141-79.

Burguet, R. and Sákovics, J. (1999) Imperfect Competition in Auction Design. International Economic Review, 40, forthcoming.

\section{Testing the Theory}

\subsection{Empirical}

* Laffont, J-J. (1997). Game Theory and Empirical Economics: The Case of Auction Data. European Economic Review, 41, 1-35.

Hendricks, K. and Porter, R. H. (1988) An Empirical Study of an Auction with Asymmetric Information. American Economic Review, 78, 865-83.

Hendricks, K. and Paarsch, H. J. (1995) A Survey of Recent Empirical Work Concerning Auctions. Canadian Journal of Economics, 28, 403-26.

Laffont, J-J, Ossard, H. and Vuong, Q. (1995) Econometrics of First-Price Auctions. Econometrica, 63, 953-80.

Porter, R. H. (1995) The Role of Information in U.S. Offshore Oil and Gas Lease Auctions. Econometrica, 63, 1-27.

Laffont, J-J and Vuong, Q. (1996) Structural Analysis of Auction Data. The American Economic Review, 86, 414-20.

\subsection{Experimental}

* Kagel, J. H. (1995) Auctions: A Survey of Experimental Research. In John H. Kagel and Alvin E. Roth (eds.), The Handbook of Experimental Economics (pp. 501-86). New Jersey: Princeton University Press.

\section{More on Specific Auction Forms}

\subsection{More on First Price Auctions}

Lebrun, B. (1996) Existence of an Equilibrium in First Price Auctions. Economic 
Theory, 7, 421-43.

Maskin, E. S. and Riley, J. G. (1996a) Equilibrium in Sealed High Bid Auctions. Mimeo, Harvard University and University of California.

Maskin, E. S. and Riley, J. G. (1996b) Uniqueness in Sealed High Bid Auctions. Mimeo, Harvard University and University of California.

Athey, S. (1997) Single-Crossing Properties and the Existence of Pure-Strategy Equilibrium in Games of Incomplete Information. Mimeo, M.I.T.

Lizzeri, A. and Persico N. (1998) Uniqueness and Existence of Equilibrium in Auctions with a Reserve Price. Working Paper, Princeton University and University of Pennsylvania.

\subsection{More on Second Price Auctions}

Rothkopf, M. H., Teisberg, T. J., and Kahn, E. P. (1990) Why are Vickrey Auctions Rare, Journal of Political Economy, 98, 94-109.

Bikhchandani, S. and Riley, J. G. (1991) Equilibria in Open Common Value Auctions. Journal of Economic Theory, 53, 101-30.

Bulow, J., Huang, M. and Klemperer, P. (1995) Toeholds and Takeovers: General Characterization, Existence, and Uniqueness of Equilibrium. Mimeo, Stanford University and Nuffield College, Oxford University.

Lopomo, G. (1998) The English Auction is Optimal among Simple Sequential Auctions. Journal of Economic Theory, 82, 144-66.

Wilson, R. (1998) Sequential equilibria of asymmetric ascending auctions: The case of log-normal distributions. Economic Theory, 12, 433-40.

Bulow, J. I. and Klemperer, P. D. (1999c) Prices and the Winner's Curse. Nuffield College, Oxford University Discussion Paper.

\section{Miscellaneous}

Cassady, R. Jr. (1967) Auctions and Auctioneering. University of California Press, Berkeley and Los Angeles.

Shubik, M. (1983) Auctions, Bidding, and Markets: An Historical Sketch. In R. Engelbrecht-Wiggans, M. Shubik, and J. Stark (eds), Auctions, Bidding, and Contracting (pp. 33-52). New York: New York University Press.

Ashenfelter, O. (1989) How Auctions Work for Wine and Art. Journal of Economic Perspectives, 3, 23-36. 
McAfee, R. P. and McMillan, J. (1994) Selling Spectrum Rights. Journal of Economic Perspectives, 8, 145-62.

McAfee, R. P and McMillan, J. (1996) Analyzing the Airwaves Auction. Journal of Economic Perspectives, 10, 159-75.

Riley, J. G. and Li, H. (1997) Auction Choice: A Numerical Analysis. Mimeo, University of California at Los Angeles.

Ginsburgh, V. (1998) Absentee Bidders and the Declining Price Anomaly in Wine Auctions. Journal of Political Economy, 106, 1302-19.

Bulow, J. I. and Klemperer, P. D. (1999b) Appendix B, The Tobacco Deal. Brookings Papers on Economic Activity (Microeconomics 2), forthcoming.

Milgrom, P. R. (forthcoming) Putting Auction Theory to Work. Cambridge: Cambridge University Press.

\section{Surveys}

* Klemperer, 1999 (see under 1).

* McAfee and McMillan, 1987 (see under 3).

Milgrom, P. R. (1985) The Economics of Competitive Bidding: A Selective Survey. In Leonid Hurwicz, David Schmeidler, and Hugo Sonnenschein (eds.), Social Goals and Social Organization: Essays in Memory of Elisha Pazner. Cambridge: Cambridge University Press.

Weber, R. J. (1985) Auctions and Competitive Bidding. In H. Peyton Young, (ed.), Fair Allocation, American Mathematical Society Proceedings of Symposia in Applied Mathematics (pp. 143-70). American Mathematical Society, Providence, Rhode Island.

Milgrom, P. R. (1987) Auction Theory. In Truman F. Bewley (ed.), Advances in Economic Theory: Fifth World Congress. Cambridge: Cambridge University Press.

Milgrom, P. R. (1989) Auctions and Bidding: A Primer. Journal of Economic Perspectives, 3, 3-22.

Riley, J. G. (1989) An Introduction to the Theory of Contests. In H. W. Kuhn and G. Szego (eds.), Incomplete Information and Bounded Rationality Decision Models. Berlin: Springer-Verlag.

Maskin, E. S. (1992) Auctions and Privatization. In H. Siebert (ed.), Privatization (pp. 115-36). 
Wilson, R. (1992) Strategic Analysis of Auctions. In R. J. Aumann and S. Hart (eds.), Handbook of Game Theory, Volume 1, (pp. 228-279). Elsevier Science Publishers.

Bikhchandani, S. and Huang, C-F. (1993) The Economics of Treasury Securities Markets. Journal of Economic Perspectives, 7, 117-34.

Harstad, R. M. and Rothkopf, M. H. (1994) Modeling Competitive Bidding: A Critical Essay. Management Science, 40, 364-84.

Rothkopf, M. H. (1994) Models of Auctions and Competitive Bidding. In S. M. Pollock et al, Handbooks in Operations Research and Management Science, Chapter 19, Vol 6. Elsevier Science.

Wolfstetter, E. (1996) Auctions: An Introduction. Journal of Economic Surveys, 10, $367-420$.

\section{Collection of Articles}

Klemperer, P. D. (1999) (ed.) The Economic Theory of Auctions. Cheltenham, UK: Edward Elgar. 


\section{References}

Anton, J. J. and Yao, D. A. (1989) Split Awards, Procurement, and Innovation. Rand Journal of Economics, 20, 538-52.

Anton, J. J. and Yao, D. A. (1992) Coordination in Split Award Auctions. Quarterly Journal of Economics, 107, 681-701.

Armstrong, M. (1998) Optimal Multi-Object Auctions. Mimeo, Oxford University.

Ashenfelter, O. (1989) How Auctions Work for Wine and Art. Journal of Economic Perspectives, 3, 23-36.

Athey, S. (1997) Single-Crossing Properties and the Existence of Pure-Strategy Equilibrium in Games of Incomplete Information. Mimeo, M.I.T.

Ausubel, L. (1998) An Efficient Ascending-Bid Auction for Multiple Objects. Working Papers, University of Maryland.

Ausubel, L. and Cramton, P. (1998) Demand Reduction and Inefficiency in Multi-Unit Auctions. Mimeo, University of Maryland.

Avery, C. and Hendershott, T. (1997) Bundling and Optimal Auctions of Multiple Goods. Mimeo, School of Government, Harvard University and Graduate School of Business, Stanford University.

Avery, C. (1998) Strategic Jump Bidding in English Auctions. Review of Economic Studies, 65, 185-210.

Back, K. and Zender, J. F. (1993) Auctions of Divisible Goods. Review of Financial Studies, 6, 733-64.

Baye, M. R., Kovenock, D., and De Vries, C. G. (1997) Fee Allocation of Lawyer Services in Litigation. Mimeo, Indiana University, Princeton University and Tinbergen 
Institute, Erasmus University.

Beggs, A. W. and Graddy, K. (1997) Declining Values and the Afternoon Effect: Evidence from Art Auctions. Rand Journal of Economics, 28, 544-65.

Benoit, J-P. and Krishna, V. (1998) Multi-Object Auctions with Budget Constrained Bidders. Working Paper, New York University and Pennsylvania State University.

Bernhardt, D. and Scoones, D. (1994) A Note on Sequential Auctions. American Economic Review, 84, 653-57.

Bernheim, B. D. and Whinston, M. D. (1986) Menu Auctions, Resource Allocation, and Economic Influence. Quarterly Journal of Economics, 101, 1-32.

Bikhchandani, S. (1988) Reputation in Repeated Second-Price Auctions. Journal of Economic Theory, 46, 97-119.

Bikhchandani, S. (1999) Auctions of Heterogeneous Objects. Games and Economic Behaviour, 26, 193-220.

Bikhchandani, S. and Huang, C-F. (1993) The Economics of Treasury Securities Markets. Journal of Economic Perspectives, 7, 117-34.

Bikhchandani, S. and Riley, J. G. (1991) Equilibria in Open Common Value Auctions. Journal of Economic Theory, 53, 101-30.

Black, J. and de Meza, D. (1992) Systematic Price Divergences Between Successive Auctions Are No Anomaly. Journal of Economics and Management Strategy, 1, 60728.

Bliss, C. and Nalebuff, B. (1984) Dragon-Slaying and Ballroom Dancing: The Private Supply of a Public Good. Journal of Public Economics, 25, 1-12.

Bolle, F. (1992) Supply Function Equilibria and the Danger of Tacit Collusion: The 
Case of Spot Markets for Electricity. Energy Economics, 14, 94-102.

Branco, F. (1997) The Design of Multidimensional Auctions. Rand Journal of Economics, 28, 63-81.

Bulow, J. I., Geanakoplos, J. D., and Klemperer, P. D. (1985a) Multimarket Oligopoly: Strategic Substitutes and Complements. Journal of Political Economy, 93, 488-511.

Bulow, J. I., Geanakoplos, J. D., and Klemperer, P. D. (1985b) Holding Idle Capacity to Deter Entry. Economic Journal, 95, 178-82.

Bulow, J. I., Huang, M., and Klemperer, P. D. (1995) Toeholds and Takeovers: General Characterization, Existence, and Uniqueness of Equilibrium. Mimeo, Stanford University and Nuffield College, Oxford University.

Bulow, J. I., Huang, M., and Klemperer, P. D. (1999) Toeholds and Takeovers. Journal of Political Economy, 107, forthcoming.

Bulow, J. I. and Klemperer, P. D. (1994) Rational Frenzies and Crashes. Journal of Political Economy, 102, 1-23.

Bulow, J. I. and Klemperer, P. D. (1996) Auctions vs. Negotiations. American Economic Review, 86, 180-94.

Bulow, J. I. and Klemperer, P. D. (1999a) The Generalized War of Attrition. American Economic Review, 89, forthcoming.

Bulow, J. I. and Klemperer, P. D. (1999b) Appendix B, The Tobacco Deal. Brookings Papers on Economic Activity (Microeconomics 2), forthcoming.

Bulow, J. I. and Klemperer, P. D. (1999c) Prices and the Winner's Curse. Nuffield College, Oxford University Discussion Paper.

Bulow, J. I. and Roberts, D. J. (1989) The Simple Economics of Optimal Auctions. 
Journal of Political Economy, 97, 1060-90.

Burguet, R. and Sákovics, J. (1996) Reserve Prices without Commitment. Games and Economic Behavior, 15, 149-64.

Burguet, R. and Sákovics, J. (1999) Imperfect Competition in Auction Design. International Economic Review, 40, forthcoming.

Caillaud, B. and Jehiel, P. (1998) Collusion in Auctions with Externalities. Rand Journal of Economics, 29, 680-702.

Capen, E. C., Clapp, R. V., and Campbell, W. M. (1971) Competitive Bidding in High-Risk Situations. Journal of Petroleum Technology, 23, 641-53.

Cassady, R. Jr. (1967) Auctions and Auctioneering. University of California Press, Berkeley and Los Angeles.

Chatterjee, K. and Samuelson, W. (1983) Bargaining under Incomplete Information. Operations Research, 31, 835-51.

Che, Y-K. (1993) Design Competition through Multidimensional Auctions. Rand Journal of Economics, 24, 668-80.

Che, Y-K. and Gale, I. L. (1996) Expected Revenue of All-Pay Auctions and FirstPrice Sealed-Bid Auctions with Budget Constraints. Economics Letters, 50, 367-71.

Che, Y-K. and Gale, I. L. (1998) Standard Auctions with Financially Constrained Bidders. Review of Economic Studies, 65, 1-21.

Cramton, P., Gibbons, R., and Klemperer, P. D. (1987) Dissolving a Partnership Efficiently. Econometrica, 55, 615-32.

Cremer, J. and McLean, R. P. (1985) Optimal Selling Strategies under Uncertainty for a Discriminatory Monopolist when Demands Are Interdependent. Econometrica, 
$53,345-61$.

Cremer, J. and McLean, R. P. (1988) Full Extraction of the Surplus in Bayesian and Dominant Strategy Auctions. Econometrica, 56, 1247-57.

Daniel, K. and Hirshleifer, D. (1995) A Theory of Costly Sequential Bidding. Mimeo, Universities of Chicago and Michigan.

Daripa, A. (1996a) Quantities Rather Than Prices: Market Allocation, Informational Free-Rides and the Value of Inside Information. Mimeo, Birkbeck College, London.

Daripa, A. (1996b) A Theory of Treasury Auctions. Mimeo, Birkbeck College, London.

Dasgupta, P. S., Hammond, P. J., and Maskin, E. S. (1979) The Implementation of Social Choice Rules: Some General Results on Incentive Compatibility. Review of Economic Studies, 46, 185-216.

Dasgupta, P. S. and Maskin, D. (1998) Efficient Auctions. Working Paper, Cambridge University and Harvard University.

Engelbrecht-Wiggans, R. (1987) Optimal Reservation Prices in Auctions. Management Science, 33, 763-70.

Engelbrecht-Wiggans, R. (1993) Optimal Auctions Revisited. Games and Economic Behaviour, 5, 227-39.

Engelbrecht-Wiggans, R. (1994) Sequential Auctions of Stochastically Equivalent Objects. Economics Letters, 44, 87-90.

Engelbrecht-Wiggans, R. and Kahn, C. M. (1998) Multi-unit Auctions with Uniform Prices. Economic Theory, 12, 227-58.

Engelbrecht-Wiggans, R. and Kahn, C. M. (1998) Multi-Unit Pay-Your-Bid Auctions with Variable Awards. Games and Economic Behavior, 23, 25-42. 
Engelbrecht-Wiggans, R., Milgrom, P. R., and Weber, R. J. (1983) Competitive Bidding and Proprietary Information. Journal of Mathematical Economics, 11, 161-69.

von der Fehr, N-H. M. (1994) Predatory Bidding in Sequential Auctions. Oxford Economic Papers, 46, 345-56.

von der Fehr, N-H. M. and Riis, C. (1999) Option Values in Sequential Markets. Mimeo, University of Oslo and Norweigian School of Management.

Fishman, M. J. (1988) A Theory of Pre-emptive Takeover Bidding. Rand Journal of Economics, 19, 88-101.

Friedman, L. (1956) A Competitive Bidding Strategy. Operations Research, 4, 104-12.

Fudenberg, D. and Tirole, J. (1986) A Theory of Exit in Duopoly. Econometrica, 54, 943-60.

Fudenberg, D. and Tirole, J. (1991) Game Theory. Cambridge, Mass.: MIT Press.

Gale, I. L. and Hausch, D. B. (1994) Bottom-Fishing and Declining Prices in Sequential Auctions. Games and Economic Behavior, 7, 318-31.

Gale, I. L., Hausch, D. B., and Stegeman, M. (1998) Sequential Procurement Auctions with Subcontracting. Mimeo, Georgetown University, University of Wisconsin and Virginia Polytechnic Institute.

Gale, I. L. and Stegeman, M. (1995) Sequential Auctions of Endogenously Valued Objects. Mimeo, Georgetown University and Virginia Polytechnic Institute.

Gibbon, E. (1776) History of the Decline and Fall of the Roman Empire. London: Strahan and Cadell.

Gibbons, R. (1992) Game Theory for Applied Economists. Princeton, New Jersey: 
Princeton University Press.

Gilbert, R. and Klemperer, P. D. (1999) An Equilibrium Theory of Rationing. Rand Journal of Economics, 30, forthcoming.

Ginsburgh, V. (1998) Absentee Bidders and the Declining Price Anomaly in Wine Auctions. Journal of Political Economy, 106, 1302-19.

Graham, D. A. and Marshall, R. C. (1987) Collusive Bidder Behavior at Single-Object Second-Price and English Auctions. Journal of Political Economy, 95, 1217-39.

Graham, D. A., Marshall, R. C., and Richard, J-F. (1990) Differential Payments within a Bidder Coalition and the Shapley Value. American Economic Review, 80, 493-510.

Green, R. J. (1996) Increasing Competition in the British Electricity Spot Market. Journal of Industrial Economics, 44, 205-16.

Green, R. J. and Newbery, D. M. (1992) Competition in the British Electricity Spot Market. Journal of Political Economy, 100, 929-53.

Griesmer, J. H., Levitan, R. E., and Shubik, M. (1967) Toward a Study of Bidding Processes Part IV: Games with Unknown Costs. Naval Research Logistics Quarterly, $14,415-33$.

Hansen, R. G. (1988) Auctions with Endogenous Quantity. Rand Journal of Economics, 19, 44-58.

Harford, T. (1998) Sequential Auctions with Financially Constrained Bidders. M.Phil thesis, Oxford University.

Harris, M. and Raviv, A. (1981) Allocation Mechanisms and the Design of Auctions. Econometrica, 49, 1477-99.

Harris, M. and Townsend, R. M. (1981) Resource Allocation Under Asymmetric In- 
formation. Econometrica, 49, 33-64.

Harstad, R. M. (1990) Alternative Common Values Auction Procedures: Revenue Comparisons with Free Entry. Journal of Political Economy, 98, 421-29.

Harstad, R.M., Kagel, J., and Levin, D. (1990) Equilibrium Bid Functions for Auctions with an Uncertain Number of Bidders. Economic Letters, 33, 35-40.

Harstad, R. M. and Rothkopf, M. H. (1994) Modeling Competitive Bidding: A Critical Essay. Management Science, 40, 364-84.

Hausch, D. B. (1986) Multi-Object Auctions: Sequential vs. Simultaneous Sales. Management Science, 32, 1599-1610.

Hendricks, K. and Paarsch, H. J. (1995) A Survey of Recent Empirical Work Concerning Auctions. Canadian Journal of Economics, 28, 403-26.

Hendricks, K. and Porter, R. H. (1988) An Empirical Study of an Auction with Asymmetric Information. American Economic Review, 78, 865-83.

Hendricks, K. and Porter, R. H. (1989) Collusion in Auctions. Annales D'Économie et de Statistique, 15/16, 217-30.

Hendricks, K., Porter, R. H., and Tan, G. (1999) Joint Bidding in Federal Offshore Oil and Gas Lease Auctions. Working Paper, University of British Columbia.

Holt, C. A. Jr. (1980) Competitive Bidding for Contracts under Alternative Auction Procedures. Journal of Political Economy, 88, 433-45.

Holt, C. A. Jr. and Sherman, R. (1982) Waiting-Line Auctions. Journal of Political Economy, 90, 280-94.

Jehiel, P. and Moldovanu, B. (1996) Strategic Nonparticipation. Rand Journal of Economics, 27, 84-98. 
Jehiel, P., Moldovanu, B., and Stacchetti, E. (1996) How (Not) to Sell Nuclear Weapons. American Economic Review, 86, 814-29.

Jehiel, P. and Moldovanu, B. (1998) Efficient Design with Interdependent Valuations. Working Paper, University College London and University of Mannheim.

Kagel, J. H. (1995) Auctions: A Survey of Experimental Research. In John H. Kagel and Alvin E. Roth (eds.), The Handbook of Experimental Economics (pp. 501-86). New Jersey: Princeton University Press.

Klemperer, P. D. (1995) Competition when Consumers have Switching Costs: An Overview with Applications to Industrial Organization, Macroeconomics, and International Trade. Review of Economic Studies, 62, 515-39.

Klemperer, P. D. (1998) Auctions with Almost Common Values. European Economic Review, 42, 757-69.

Klemperer, P. D. (1999) (ed.) The Economic Theory of Auctions. Cheltenham, UK: Edward Elgar.

Klemperer, P. D. and Meyer, M. A. (1989) Supply Function Equilibria in Oligopoly Under Uncertainty. Econometrica, 57, 1243-77.

Krishna, K. (1993) Auctions with Endogenous Valuations: The Persistence of Monopoly Revisited. American Economic Review, 83, 147-60.

Krishna, V. and Morgan, J. (1997) An Analysis of the War of Attrition and the AllPay Auction. Journal of Economic Theory, 72, 343-62.

Laffont, J-J. (1997). Game Theory and Empirical Economics: The Case of Auction Data. European Economic Review, 41, 1-35.

Laffont, J-J, Ossard, H. and Vuong, Q. (1995) Econometrics of First-Price Auctions. 
Econometrica, 63, 953-80.

Laffont, J-J. and Tirole, J. (1987) Auctioning Incentive Contracts. Journal of Political Economy, 95, 921-37.

Laffont, J-J and Vuong, Q. (1996) Structural Analysis of Auction Data. The American Economic Review, 86, 414-20.

Lebrun, B. (1996) Existence of an Equilibrium in First Price Auctions. Economic Theory, 7, 421-43.

Leininger, W., Linhart, P. B., and Radner, R. (1989) Equilibria of the Sealed Bid Mechanism for Bargaining with Incomplete Information. Journal of Economic Theory, 48, 63-106.

Levin, J. (1997) Auctions for Complements and Substitutes. Working Paper, M.I.T.

Levin, D. and Smith, J. L. (1994) Equilibrium in Auctions with Entry. American Economic Review, 84, 585-99.

Levin, D. and Smith, J. L. (1996a) Optimal Reservation Prices in Auctions. Economic Journal, 106, 1271-83.

Levin, D. and Smith, J. L. (1996b) Ranking Auctions with Risk Averse Bidders. Journal of Economic Theory, 68, 549-61.

Lizzeri, A. and Persico N. (1998) Uniqueness and Existence of Equilibrium in Auctions with a Reserve Price. Working Paper, Princeton University and University of Pennsylvania.

Lopomo, G. (1998) The English Auction is Optimal among Simple Sequential Auctions. Journal of Economic Theory, 82, 144-66.

Lucking-Reiley, D. (1998) Vickrey Auctions Predate Vickrey. Mimeo, Vanderbilt Uni- 
versity.

Mailath, G. J. and Zemsky, P. (1991) Collusion in Second Price Auctions with Heterogeneous Bidders. Games and Economic Behavior, 3, 467-86.

Manelli, A. M. and Vincent, D. R. (1995) Optimal Procurement Mechanisms. Econometrica, 63, 591-620.

Marshall, R. C., Meurer, M. J., Richard, J-F., and Stromquist, W. (1994) Numerical Analysis of Asymmetric First Price Auctions. Games and Economic Behaviour, 7, 193-220.

Maskin, E. S. (1992) Auctions and Privatization. In H. Siebert (ed.), Privatization (pp. 115-36).

Maskin, E. S. and Riley, J. G. (1984) Optimal Auctions with Risk Averse Buyers. Econometrica, 52, 1473-1518.

Maskin, E. S. and Riley, J. G. (1985) Auction Theory with Private Values. American Economic Review, 75, 150-55.

Maskin, E. S. and Riley, J. G. (1989) Optimal Multi-Unit Auctions. In Frank Hahn (ed.), The Economics of Missing Markets, Information, and Games (pp. 312-335). Oxford: Oxford University Press, Clarendon Press.

Maskin, E. S. and Riley, J. G. (1996a) Equilibrium in Sealed High Bid Auctions. Mimeo, Harvard University and University of California.

Maskin, E. S. and Riley, J. G. (1996b) Uniqueness in Sealed High Bid Auctions. Mimeo, Harvard University and University of California.

Maskin, E. S. and Riley, J. G. (1999) Asymmetric Auctions. Review of Economic Studies, forthcoming. 
Matthews, S. A. (1983) Selling to Risk Averse Buyers with Unobservable Tastes. Journal of Economic Theory, 3, 370-400.

Matthews, S. A.(1984) Information Acquisition in Discriminatory Auctions. In M. Boyer and R. E. Kihlstrom (eds.), Bayesian Models in Economic Theory (pp. 181207). New York: North Holland.

Matthews, S. A. (1987) Comparing Auctions for Risk-Averse Buyers: A Buyer's Point of View. Econometrica, 55, 633-46.

Maxwell, C. (1983) Auctioning Divisible Commodities: A Study of Price Determination. PhD Dissertation, Harvard University.

McAfee, R. P. (1992) A Dominant Strategy Double Auction. Journal of Economic Theory, 56, 434-50.

McAfee, R. P. (1993) Mechanism Design by Competing Sellers. Econometrica, 61, 1281-1312.

McAfee, R. P. and McMillan, J. (1986) Bidding for Contracts: A Principal-Agent Analysis. Rand Journal of Economics, 17, 326-38.

McAfee, R. P. and McMillan, J. (1987a) Auctions and Bidding. Journal of Economic Literature, 25, 699-738.

McAfee, R. P. and McMillan, J. (1987b) Auctions with a Stochastic Number of Bidders. Journal of Economic Theory, 43, 1-19.

McAfee, R. P. and McMillan, J. (1987c) Auctions with Entry. Economics Letters, 23, $343-47$.

McAfee, R. P. and McMillan, J. (1987d) Competition for Agency Contracts. Rand Journal of Economics, 18, 296-307. 
McAfee, R. P. and McMillan, J. (1988) Search Mechanisms. Journal of Economic Theory, 44, 99-123.

McAfee, R. P. and McMillan, J. (1989) Government Procurement and International Trade. Journal of International Economics, 26, 291-308.

McAfee, R. P and McMillan, J. (1992) Bidding Rings. American Economic Review, 82, 579-99.

McAfee, R. P. and McMillan, J. (1994) Selling Spectrum Rights. Journal of Economic Perspectives, 8, 145-62.

McAfee, R. P and McMillan, J. (1996) Analyzing the Airwaves Auction. Journal of Economic Perspectives, 10, 159-75.

McAfee, R. P., McMillan, J., and Reny, P. J. (1989) Extracting the Surplus in the Common Value Auction. Econometrica, 57, 1451-60.

McAfee, R. P. and Reny, P. J. (1992) Correlated Information and Mechanism Design. Econometrica, 60, 395-421.

McAfee, R. P. and Vincent, D. (1993) The Declining Price Anomaly. Journal of Economic Theory, 60, 191-212.

McAfee, R. P. and Vincent, D. (1997) Sequentially Optimal Auctions. Games and Economic Behaviour, 18, 246-76.

Menezes, F. M. and Monteiro, P. K. (1997) Auctions with Endogenous Participation. Mimeo, Australian National University and IMPA.

Milgrom, P. R. (1979) A Convergence Theorem for Competitive Bidding with Differential Information. Econometrica, 47, 679-88.

Milgrom, P. R. (1981) Rational Expectations, Information Acquisition, and Competi- 
tive Bidding. Econometrica, 49, 921-43.

Milgrom, P. R. (1985) The Economics of Competitive Bidding: A Selective Survey. In Leonid Hurwicz, David Schmeidler, and Hugo Sonnenschein (eds.), Social Goals and Social Organization: Essays in Memory of Elisha Pazner. Cambridge: Cambridge University Press.

Milgrom, P. R. (1987) Auction Theory. In Truman F. Bewley (ed.), Advances in Economic Theory: Fifth World Congress. Cambridge: Cambridge University Press.

Milgrom, P. R. (1989) Auctions and Bidding: A Primer. Journal of Economic Perspectives, 3, 3-22.

Milgrom, P. R. (forthcoming) Putting Auction Theory to Work. Cambridge: Cambridge University Press.

Milgrom, P. R. and Roberts, D. J. (1982) Limit Pricing and Entry under Incomplete Information: An Equilibrium Analysis. Econometrica, 50, 443-59.

Milgrom, P. R. and Weber, R. J. (1982a) A Theory of Auctions and Competitive Bidding. Econometrica, 50, 1089-1122.

Milgrom, P. R. and Weber, R. J. (1982b) The Value of Information in a Sealed-Bid Auction. Journal of Mathematical Economics, 10, 105-14.

Milgrom, P. R. and Weber, R. J. (1982c) A Theory of Auctions and Competitive Bidding II. Mimeo, Stanford University and Northwestern University.

Mirrlees, J. A. (1971) An Exploration in the Theory of Optimum Income Taxation. Review of Economic Studies, 38, 175-208.

Myerson, R. B. (1979) Incentive Compatibility and the Bargaining Problem. Econometrica, 47, 61-73. 
Myerson, R. B. (1981) Optimal Auction Design. Mathematics of Operations Research, 6, 58-73.

Myerson, R. B. and Satterthwaite, M. A. (1983) Efficient Mechanisms for Bilaterial Trade. Journal of Economic Theory, 29, 265-81.

Nyborg, K. G. (1997) On Complicity in Share Auctions. Mimeo, London Business School.

Ortega-Reichert, A. (1968) Models for Competitive Bidding Under Uncertainty. Stanford University PhD thesis (and Technical Report No. 8, Department of Operations Research, Stanford University).

Ortega-Reichert, A. (1968) A Sequential Game with Information Flow. Chapter 8 in Models for Competitive Bidding Under Uncertainty, Stanford University PhD thesis (and Technical Report No. 8, Department of Operations Research, Stanford University) (pp. 232-54).

Palfrey, T. R. (1983) Bundling Decisions by a Multiproduct Monopolist with Incomplete Information. Econometrica, 51, 463-84.

Perry, M. and Reny, P. J. (1998) Ex-Post Efficient Auctions for Agents with Interdependent Values. Working Paper, Hebrew University of Jerusalem and University of Pittsburgh.

Perry, M. and Reny, P. J. (forthcoming) On the Failure of the Linkage Principle in Multi-Unit Auctions. Econometrica.

Persico, N. (1997) Information Acquisition in Auctions. Working Paper, U.C.L.A.

Pesendorfer, W. and Swinkels, J. M. (1997) The Loser's Curse and Information Aggregation in Common Value Auctions. Econometrica, 65, 1247-81.

Peters, M. and Severinov, S. (1997) Competition Among Sellers Who Offer Auctions 
Instead of Prices. Journal of Economic Theory, 75, 141-79.

Piccione, M. and Tan, G. (1996) A Simple Model of Expert and Non Expert Bidding in First Price Auctions. Journal of Economic Theory, 70, 501-15.

Pitchik, C. (1995) Budget-Constrained Sequential Auctions with Incomplete Information. Mimeo, University of Toronto.

Pitchik, C. and Schotter, A. (1988) Perfect Equilibria in Budget Constrained Sequential Auctions: An Experimental Study. Rand Journal of Economics, 19, 363-88.

Porter, R. H. (1995) The Role of Information in U.S. Offshore Oil and Gas Lease Auctions, Econometrica, 63, 1-27.

Reece, D. K. (1979) An Analysis of Alternative Bidding Systems for Leasing Offshore Oil. Bell Journal of Economics, 10, 659-69.

Riley, J. G. (1980) Strong Evolutionary Equilibrium and The War of Attrition. Journal of Theoretical Biology, 82, 383-400.

Riley, J. G. (1988), Ex Post Information in Auctions. Review of Economic Studies, 55, 409-30.

Riley, J. G. (1989) Expected Revenue from Open and Sealed Bid Auctions. Journal of Economic Perspectives, 3, 41-50.

Riley, J. G. (1989) An Introduction to the Theory of Contests. In H. W. Kuhn and G. Szego (eds.), Incomplete Information and Bounded Rationality Decision Models. Berlin: Springer-Verlag.

Riley, J. G. and Li, H. (1997) Auction Choice: A Numerical Analysis. Mimeo, University of California at Los Angeles.

Riley, J. G. and Samuelson, W. F. (1981) Optimal Auctions. American Economic 
Review, 71, 381-92.

Riordan, M. H. and Sappington, D. E. M. (1987) Awarding Monopoly Franchises. American Economic Review, 77, 375-87.

Robert, J. (undated, $\approx 1995)$ Sequential Descending-Price Auctions with Multi-Unit Demand. Mimeo, Université de Montreal.

Robert, J., Laffont, J-J., and Loisel, P. (1994) Repeated Descending-Price Auctions I: Theory. Mimeo, Université de Montreal, Université de Toulouse, and INRA.

Robinson, M. S. (1985) Collusion and the Choice of Auction. Rand Journal of Economics, 16, 141-45.

Rosenthal, R. W. (1980) A Model in which an Increase in the Number of Sellers Leads to a Higher Price. Econometrica, 48, 1575-79.

Rothkopf, M. H. (1969) A Model of Rational Competitive Bidding. Management Science, 15, 362-73.

Rothkopf, M. H. (1980) On Multiplicative Bidding Strategies. Operations Research, $25,570-75$.

Rothkopf, M. H. (1994) Models of Auctions and Competitive Bidding. In S. M. Pollock et al, Handbooks in Operations Research and Management Science, Chapter 19, Vol 6. Elsevier Science.

Rothkopf, M. H., Harstad, R. M., and Fu, Y. (1997) Is Subsidizing Inefficient Bidders Actually Costly? Mimeo, Rutgers University.

Rothkopf, M. H., Teisberg, T. J., and Kahn, E. P. (1990) Why are Vickrey Auctions Rare, Journal of Political Economy, 98, 94-109.

Rothkopf, M. H., Pekeč, A., and Harstad, R. M. (1998) Computationally Manageable 
Auctions. Working Paper, Faculty of Management and Rutgers Center for Operations Research, Rutgers University.

Rustichini, A., Satterthwaite, M. A., and Williams, S. R. (1994) Convergence to Efficiency in a Simple Market with Incomplete Information. Econometrica, 62, 1041-63.

Satterthwaite, M. A. and Williams, S. R. (1989a) The Rate of Convergence to Efficiency in the Buyer's Bid Double Auction as the Market Becomes Large. Review of Economic Studies, 56, 477-98.

Satterthwaite, M. A. and Williams, S. R. (1989b) Bilateral Trade with the Sealed Bid k-Double Auction: Existence and Efficiency. Journal of Economic Theory, 48, 107-33.

Shubik, M. (1983) Auctions, Bidding, and Markets: An Historical Sketch. In R. Engelbrecht-Wiggans, M. Shubik, and J. Stark (eds), Auctions, Bidding, and Contracting (pp. 33-52). New York: New York University Press.

Vickrey, W. (1961) Counterspeculation, Auctions, and Competitive Sealed Tenders. Journal of Finance, 16, 8-37.

Vickrey, W. (1962) Auction and Bidding Games. In Recent Advances in Game Theory (pp. 15-27). Princeton, New Jersey: The Princeton University Conference.

Vickrey, W. (1976) Auctions Markets and Optimum Allocations. In Y. Amihud (ed.,) Bidding and Auctioning for Procurement and Allocation (pp. 13-20). Studies in Game Theory and Mathematical Economics. New York: New York University Press.

Waehrer, K., Harstad, R. M. and Rothkopf, M. H. (1998) Auction Form Preferences of Risk-Averse Bidtakers. Rand Journal of Economics, 29, 179-192.

Wang, J. J. D. and Zender, J. F. (1998) Auctioning Divisible Goods. Working Paper, Duke University and University of Utah.

Weber, R. J. (1983) Multi-Object Auctions. In Richard Engelbrecht-Wiggans, Martin 
Shubik, and Robert M. Stark (eds), Auctions, Bidding, and Contracting (pp. 165-91). New York: New York University Press.

Weber, R. J. (1985) Auctions and Competitive Bidding. In H. Peyton Young, (ed.), Fair Allocation, American Mathematical Society Proceedings of Symposia in Applied Mathematics (pp. 143-70). American Mathematical Society, Providence, Rhode Island.

Wilson, R. (1967) Competitive Bidding with Asymmetric Information. Management Science, 13, A816-20.

Wilson, R. (1969) Competitive Bidding with Disparate Information. Management Science, 15, 446-48.

Wilson, R. (1977) A Bidding Model of Perfect Competition. Review of Economic Studies, 44, 511-18.

Wilson, R. (1979) Auctions of Shares. Quarterly Journal of Economics, 93, 675-89.

Wilson, R. (1985) Incentive Efficiency of Double Auctions. Econometrica, 53, 1101-15.

Wilson, R. (1992) Strategic Analysis of Auctions. In R. J. Aumann and S. Hart (eds.), Handbook of Game Theory, Volume 1, (pp. 228-279). Elsevier Science Publishers.

Wilson, R. (1998) Sequential equilibria of asymmetric ascending auctions: The case of log-normal distributions. Economic Theory, 12, 433-40.

Wolfstetter, E. (1996) Auctions: An Introduction. Journal of Economic Surveys, 10, 367-420. 